\title{
Raquel Berg
}

\section{Desamparo aprendido e ilusão de controle em portadores de transtorno do jogo e controles normais}

Tese apresentada à Faculdade de Medicina da Universidade de São Paulo para obtenção do título de Doutor em Ciências

Programa de Psiquiatria

Orientador: Prof. Dr. Hermano Tavares

São Paulo

2021 


\section{Raquel Berg}

\section{Desamparo aprendido e ilusão de controle em portadores de transtorno do jogo e controles normais}

Tese apresentada à Faculdade de Medicina da Universidade de São Paulo para obtenção do título de Doutor em Ciências

Programa de Psiquiatria

Orientador: Prof. Dr. Hermano Tavares

São Paulo

2021 


\section{Dados Internaclonals de Catalogac̣ão na Publlcac̣ão (CIP)}

Preparada pela Biblioteca da

Faculdade de Medicina da Universidade de Såo Paulo

Oreproduçåo autorizada pelo autor

Berg, Raquel

Desamparo aprendido e ilusảo de controle em

portadores de transtorno do jogo e controles normais

/ Raquel Berg. -- São Paulo, 2020.

Tese(doutorado)--Faculdade de Medicina da

Universidade de São Paulo.

Programa de Psiquiatria.

Orientador: Hermano Tavares.

Descritores: 1.Desamparo aprendido 2.Ilusäo 3. Superstiçōes 4.Distorção da percepçäo 5.Transtornos disruptivos, de controle do impulso e da conduta 6.Jogo de azar

USP/FM/DBD-178/20

Responsável: Erinalva da Conceiçăo Batista, CRB-8 6755 
Aos meus queridos filhos, Ícaro e Heitor; ao meu eterno e amado marido, Márcio; e a toda a minha família; por seu amor e parceria, sempre. 


\section{AGRADECIMENTOS}

Ao Prof. Dr. Hermano Tavares, por ter me dado a chance de retornar à universidade para desenvolver esse projeto, por ter dedicado seu tempo a me orientar e a me ensinar novamente a fazer pesquisa, por sua paciência frente às inúmeras mudanças de minha vida, por sua visão criativa e abertura ao novo, e por sua constante disposição em me orientar e fazer de mim uma profissional melhor.

A Iñaki Merino Terron, por ter gentilmente desenvolvido o software do projeto desde a iniciação científica e tido todos os cuidados com as diferenças de idioma, programa esse que foi o ponto fundamental para o início desse trabalho e sem o qual nada disso teria sido possível.

À minha mãe Heloisa Maria Soares de Araujo Berg, que me ajudou em todas as etapas desse trabalho e fez o impossível se tornar possível, sendo uma verdadeira parceira nesse estudo.

Aos jogadores e controles que participaram da pesquisa, por sua generosidade em contribuir voluntariamente para esse estudo e fornecer todos os dados necessários.

Aos meus irmãos Alice, Rebeca e Edgar, por toda sua ajuda durante as disciplinas e aplicações, possibilitando que eu continuasse minha pesquisa mesmo na maternidade.

A meus amigos, familiares e colegas de trabalho pelo apoio na coleta de dados.

A meu pai Artur e sua esposa Marta, por seu amor.

Ao programa de Pós-graduação do departamento de Psiquiatra e à Comissão de Pesquisa, em especial a Eliza Fukushima, Isabel Ataíde, Lucas Marmitt e Denise Lungwtz Ramalho, pela atenção e constante disponibilidade em ajudar durante todo o período em que estive cursando o doutorado.

Aos colaboradores e ex-colaboradores do PRO-AMJO que direta ou indiretamente contribuíram com esse projeto. Em especial, a Ana Claudia Penna, Ana Yaemi Hayashiuchi, Cristiana Nicoli de Mattos, Daniel Carr Gulassa, Fabricio Ronchi, Isabela Mafra, Juan David Tovar, Leandro Requião, Leticia Croccoli e Mirella Martins de Castro Mariani por seu apoio na disponibilização de informações.

Às bancas de qualificação e de defesa, pela análise criteriosa e contribuições para a melhoria desse estudo.

À coordenação de aperfeiçoamento de pessoal de nível superior pelo apoio financeiro para a realização desse trabalho, e à Universidade de São Paulo, por ter me 
dado todos os recursos para ser a profissional que sou hoje e por ter me ensinado a acreditar nos meus sonhos.

O presente trabalho foi realizado com apoio da Coordenação de Aperfeiçoamento de Pessoal de Nível Superior - Brasil (CAPES) - Código de Financiamento 001. 
"No jogo da vida não há disputa, duelo e derrota Não vence o mais rápido, o mais esperto e nem o que mais se esforça No jogo da vida a incerteza é uma carta marcada E vence quem sempre aprende, quem se reinventa e se joga!”

Márcio Lorencini 
Esta dissertação ou tese está de acordo com as seguintes normas, em vigor no momento desta publicação:

Referências: adaptado de International Committee of Medical Journals Editors (Vancouver).

Universidade de São Paulo. Faculdade de Medicina. Divisão de Biblioteca e Documentação. Guia de apresentação de dissertações, teses e monografias. Elaborado por Anneliese Carneiro da Cunha, Maria Julia de A. L. Freddi, Maria F. Crestana, Marinalva de Souza Aragão, Suely Campos Cardoso, Valéria Vilhena. 3a ed. São Paulo: Divisão de Biblioteca e Documentação; 2011.

Abreviaturas dos títulos dos periódicos de acordo com List of Journals Indexed in Index Medicus. 


\section{Sumário}

Lista de abreviaturas e siglas

Lista de figuras

Lista de tabelas

Resumo

Summary

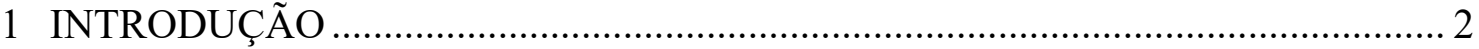

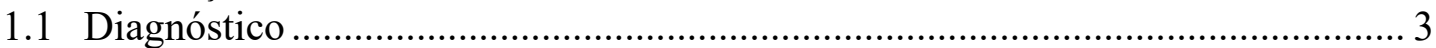

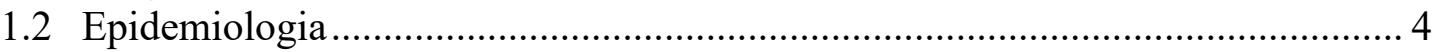

1.3 Comorbidades e relações genéticas e bioquímicas .............................................. 5

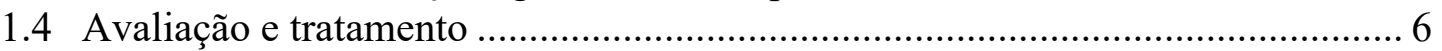

1.5 Desamparo aprendido, ilusão de controle e superstição ..................................... 8

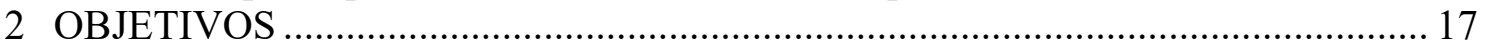

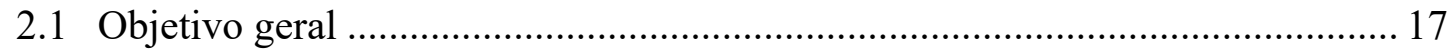

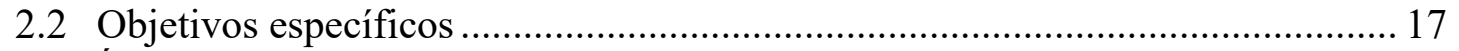

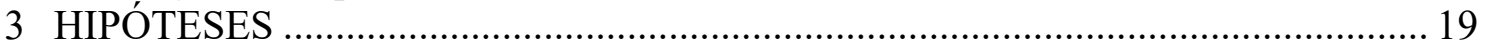

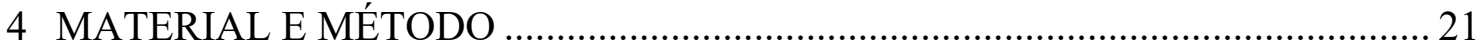

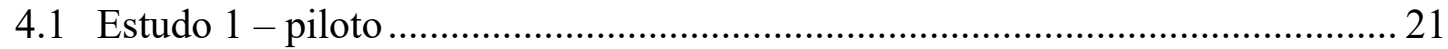

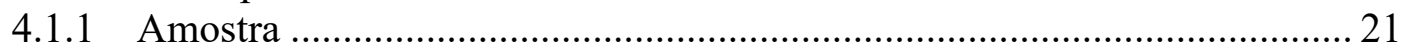

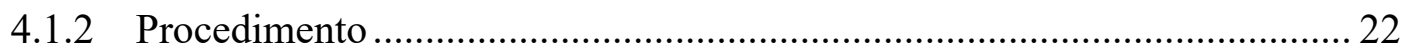

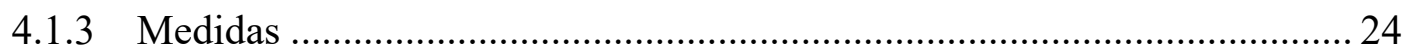

4.1.4 Considerações Éticas ....................................................................... 25

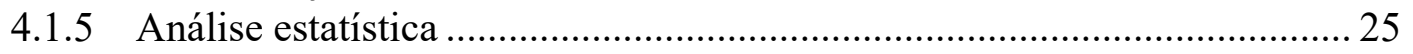

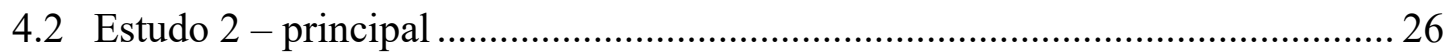

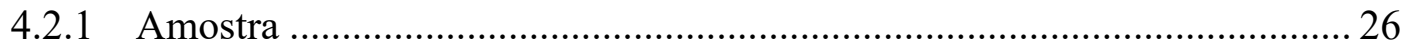

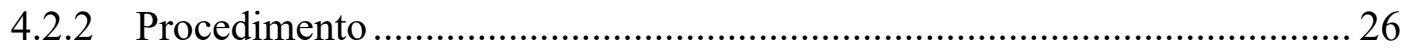

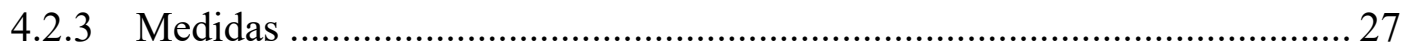

4.2.4 Considerações Éticas ........................................................................... 28

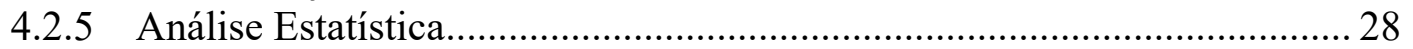

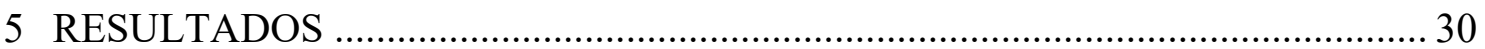

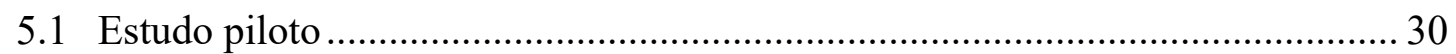

5.1.1 Comparação do desempenho de PJ e CN no TCARC - versão CS ........... 34

5.1.2 Comparação do desempenho do PJ e CN no TCARC - versão SS............. 36

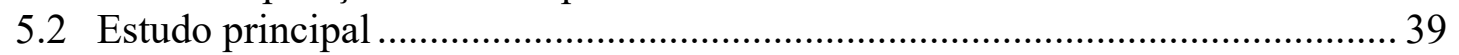

5.2.1 Comparação do desempenho de PJ e CN no TLARC - versão CS ............. 44

5.2.2 Comparação do desempenho de PJ e CN no TLARC - versão SS ............. 46

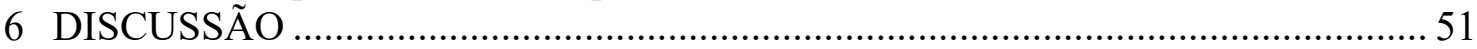

6.1 Comparação entre versões CS e SS - TCARC e TLARC ...................................51

6.2 Comparação PJ e CN - TCARC e TLARC na versão CS .................................... 53

6.3 Comparação PJ e CN - TCARC e TLARC na versão SS ................................... 54

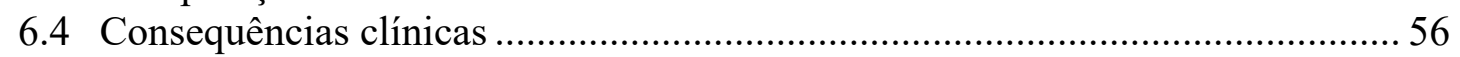

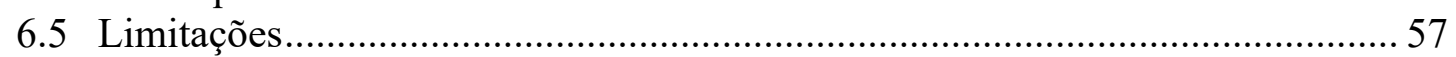

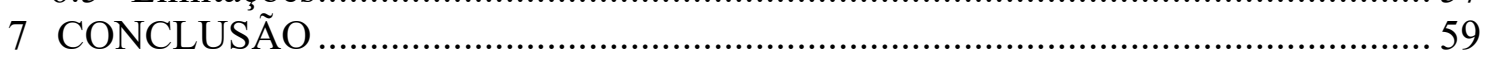

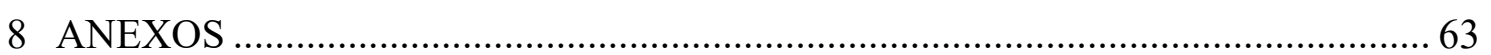

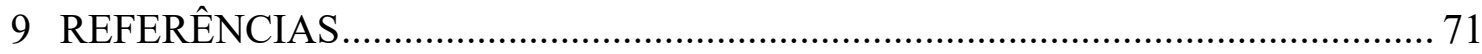




\section{LISTA DE ABREVIATURAS E SIGLAS}

APA

CAPPesq

CID

CS

DSM-III

DSM-5

IPQ-HC-FMUSP

JA

PJ

PRO-AMJO

QDSD

SRQ

SS

TCLE

TCARC

TLARC

TDAH

TJ

USP
Associação Americana de Psiquiatria

Comissão de Ética para Análise de Projetos de Pesquisa

International Statistical Classification of Diseases and Related

Health Problems

Controles Normais

Versão Com Solução (TCARC ou TLARC)

Manual Diagnóstico e Estatístico de Transtornos Mentais $-3^{\text {a }}$

Edição

Manual Diagnóstico e Estatístico de Transtornos Mentais $-5^{\mathrm{a}}$

Edição

Instituto de Psiquiatria do Hospital das Clínicas da Faculdade de

Medicina da Universidade de São Paulo

Jogadores Anônimos

Portadores de Transtorno do Jogo

Programa Ambulatorial de Jogo

Questionário de Dados Sociodemográfico

Self Repport Questionnaire

Versão Sem Solução (TCARC ou TLARC)

Termo de Consentimento Livre e Esclarecido

Teste Curto de Análise de Resposta-Consequência

Teste Longo de Análise de Resposta-Consequência

Transtorno do Déficit de Atenção e Hiperatividade

Transtorno do Jogo

Universidade de São Paulo 


\section{LISTA DE FIGURAS}

Figura 1 - Fluxograma de triagem e aplicação em PJ e CN - estudo piloto ............ 30

Figura 2 - Fluxograma de triagem e aplicação em PJ e CN - estudo principal ...... 38 


\section{LISTA DE TABELAS}

Tabela 1 - Perfil sócio-demográfico de portadores de Transtorno do Jogo (PJ) e controles normais $(\mathrm{CN})$ selecionados para participar do estudo piloto $(\mathrm{N}=40)$

Tabela 2 - Comparação de desempenho nos testes curtos de análise respostaconsequência (TCARC) entre as versões sem solução (SS) e com solução (CS) $(\mathrm{N}=40)$

Tabela 3 - Comparação de desempenho no teste curto de análise respostaconsequência (TCARC) entre portadores de Transtorno do Jogo (PJ) e controles normais $(\mathrm{CN})$ na versão com solução $(\mathrm{CS})(\mathrm{N}=40)$

Tabela 4 - Comparação de desempenho no teste curto de análise respostaconsequência (TCARC) entre portadores de Transtorno do Jogo (PJ) e controles normais $(\mathrm{CN})$ na versão sem solução $(\mathrm{SS})(\mathrm{N}=40)$................. 36

Tabela 5 - Perfil sócio-demográfico de portadores de Transtorno do Jogo (PJ) e controles normais $(\mathrm{CN})$ selecionados para participar do estudo principal $(\mathrm{N}=68)$

Tabela 6 - Comparação de desempenho nos testes longos de análise respostaconsequência (TLARC) entre as versões sem solução (SS) e com solução (CS) $(\mathrm{N}=68)$

Tabela 7 - Análise de concordância entre o autorrelato e o registro computadorizado para o uso de estratégia $(\mathrm{N}=68)$

Tabela 8 - Comparação de desempenho no teste longo de análise respostaconsequência (TLARC) entre portadores de Transtorno do Jogo (PJ) e controles normais $(\mathrm{CN})$ na versão com solução $(\mathrm{CS})(\mathrm{N}=68)$

Tabela 9 - Comparação de desempenho no teste longo de análise respostaconsequência (TLARC) entre portadores de Transtorno do Jogo (PJ) e controles normais $(\mathrm{CN})$ na versão com solução $(\mathrm{CS})$ (regressão logística, $\mathrm{N}=68)$

Tabela 10 - Comparação de desempenho no teste longo de análise respostaconsequência (TLARC) entre portadores de Transtorno do Jogo (PJ) e controles normais $(\mathrm{CN})$ na versão sem solução $(\mathrm{SS})(\mathrm{N}=68)$.

Tabela 11 - Comparação de desempenho no teste longo de análise respostaconsequência (TLARC) entre portadores de Transtorno do Jogo (PJ) e controles normais $(\mathrm{CN})$, versão sem solução $(\mathrm{SS})$ (regressão logística, $\mathrm{N}=68$ ) 


\section{RESUMO}

Berg R. Desamparo aprendido e ilusão de controle em portadores de transtorno do jogo e controles normais [Tese]. São Paulo: Faculdade de Medicina, Universidade de São Paulo; 2021.

O Transtorno do Jogo (TJ) é caracterizado por apostas persistentes, mesmo com consequentes prejuízos financeiros e sociais. Os estudos sobre esse transtorno têm relacionado o comportamento de jogo com condicionamento, distorções cognitivas e comportamento supersticioso. Estudos prévios demonstraram que, em testes analíticos de resposta-consequência com indivíduos normais, a ausência de feedback impede a extinção do comportamento e permite o desenvolvimento de comportamento supersticioso e ilusão de controle. O TJ pode ser considerado como um paradigma de resposta-consequência no qual os portadores de $\mathrm{TJ}(\mathrm{PJ})$ falham em perceber o feedback de erro. Portanto, isso significa que eles não percebem a independência entre resposta e consequência e permanecem no ato de jogar. $\mathrm{O}$ objetivo desse trabalho foi comparar o desempenho de PJ e controles normais $(\mathrm{CN})$ frente a teste curto e um teste longo de análise de resposta-consequência (TCARC com 10 repetições no estudo piloto e TLARC com 50 repetições no estudo principal), sendo que cada teste possui uma versão com solução (CS) e uma versão sem solução (SS), todas com feedback de erro. Para os estudos, selecionamos $20 \mathrm{PJ}$ e $20 \mathrm{CN}$ no estudo piloto, e $34 \mathrm{PJ}$ e $34 \mathrm{CN}$ no estudo principal, foram recrutados para participar dos estudos; metade de cada amostra foi designada para fazer a sequência CS-SS, e a outra metade realizou a sequência inversa (SS-CS). Comparados com os CN, no TCARC os PJ relataram mais ansiedade na versão CS, menos uso de estratégia e menos crença na existência de uma senha em ambas as versões, e maior quantidade de digitação aleatória em ambas as versões. No TLARC, comparados com os CN os PJ apresentaram mais ansiedade, menos felicidade e menor percepção de controle na versão $\mathrm{CS}$; na versão SS, os PJ apresentaram mais digitação aleatória, mais comportamento supersticioso e menor crença na existência de uma senha. Os PJ também apresentaram menor confiança em ambas as versões. Em contraste com achados anteriores, os PJ não demonstraram mais ilusão de controle em comparação aos CN e também se mostraram mais céticos com relação à controlabilidade de ambas as versões nos dois estudos. Nossos achados sugerem que a natureza dos testes com feedback de erro permitiu identificar déficits cognitivos que precedem o TJ, e que possivelmente poderão levar a condicionamento por reforçamento intermitente enquanto o indivíduo tenta encontrar uma solução baseado em respostas aleatórias.

Descritores: Desamparo aprendido; Ilusão; Superstições; Distorção da percepção; Transtornos disruptivos, de controle do impulso e da conduta; Jogo de azar. 


\section{SUMMARY}

Berg R. Learned helplessness and illusion of control in pathological gamblers and healthy controls [thesis]. São Paulo: "Faculdade de Medicina, Universidade de São Paulo"; 2021.

Gambling Disorder (GD) is characterized by persistent betting in even in face of accruing debts and psychosocial hardship. Studies based on this disorder have linked gambling behavior to conditioning, cognitive distortions and superstitious behavior. Previous studies have demonstrated that during Response-Outcome Analytical Tests with normal controls, the absence of feedback preclude the extinction of behavior and allow the development of superstitious behaviors and illusion of control instead. GD can be regarded as a ROAT paradigm where disordered gamblers (DG) fail to compute failure feedback. Hence they do not perceive the independence between response and outcome and continue gambling. The objective was to compare the performance between DG and controls in a short ROAT (with 10 repetitions in pilot study) and in a long ROAT (with 50 repetitions in main study), considering that in each ROAT there are two versions, a controllable and an uncontrollable one, both with explicit failure feedback. For both studies, we recruited 20 DG and 20 controls in pilot study, and 34 DG and 34 controls in main study, were recruited to be part of these studies; half of each sample was designed to do the sequence controllable-uncontrollable and the other half did the reverse sequence. In short ROAT, compared to controls DG reported more anxiety in the controllable version, less use of strategy, less belief in the existence of a key and more random typing in both versions. In long ROAT, compared to controls DG reported more anxiety, less happiness and less perception of control in the controllable version; in the uncontrollable version, DG presented more random typing, more superstitious behavior and less belief in the existence of a key. DG also reported less confidence in both versions. In contrast to previous findings, DG did not presented more illusion of control comparing to controls and they also were more skeptical about the controllability of both versions in both studies. Our findings suggest that the nature of our ROAT versions with failure feedback uncovered deficits in cognitive control in DG that precede illusion of control and superstitious behaviors, which lately could lead to conditioning by intermittent reinforcement while the individual is pursuing an outcome through random responses.

Descriptors: Learned helplessness; Illusions; Superstition; Perceptual distortion; Disruptive impulse control and conduct disorders; Gambling. 
1. INTRODUÇÃO 


\section{INTRODUÇÃO}

Os jogos de azar fazem parte do repertório comportamental humano há muito tempo, bem como a falta de controle do jogar. Historicamente, a terminologia "jogos de azar" foi criada como uma referência à forma injusta ou trapaceira de jogar (Schwartz, 2013) e somente mais tarde é que esse termo passou a ser relacionado à tentativa de ganhar algo (principalmente ganhos financeiros) por meio de apostas ou atividades com resultado determinado, em grande parte, pela sorte ou acaso - ou seja, com pouco ou nenhum envolvimento das habilidades do jogador (Ferentzy; Turner, 2013).

Em diversos países com registros históricos sobre o tema há relatos da existência dos jogos de azar em suas diversas formas - com cartas, animais, carros, roletas, dados, etc. (McMillen, 2005) -, incluindo ou não a participação do estado na regulamentação e condução dos jogos. Uma das produções mais conhecidas sobre essa patologia é o livro de Fiódor Dostoiéviski de 1867 chamado "Um jogador" (2004), no qual ele relata os dilemas e desafios do personagem quanto à sua necessidade de jogar, e sobre as sensações de prazer que o personagem tem com o jogo. O TJ (Transtorno do Jogo) tem ganhado cada vez mais importância com o surgimento dos jogos virtuais (Gainsbury, 2015), e em função desse aumento na acessibilidade, o perfil dos jogadores tem se diversificado com relação a idade e status socioeconômico.

No Brasil, a primeira loteria foi instituída por D. João VI, em 1809, com o objetivo de financiar a construção do teatro de Salvador; em 1946, as casas de jogos foram proibidas por lei, e em 1967 as loterias existentes foram regulamentadas. Em 1993, por medida de lei, foi vinculado o funcionamento de bingos para financiar o esporte, e em 1996 as loterias foram introduzidas legalmente na programação televisiva. Atualmente, os jogos de azar são parcialmente proibidos no Brasil, sendo as loterias e as corridas de cavalos como as únicas formas ainda legalizadas (Tavares, 2014).

Os jogos de azar movimentam significativo volume financeiro por todo o mundo (Nelson et al., 2008; Schwartz, 2013) e suas adaptações ou novas modalidades acompanham as mudanças do mercado. Os jogos de azar são uma atividade recreativa bastante popular, e 12\% dos adultos brasileiros relatam engajamento em jogos de azar em suas atividades mensais (Tavares et al., 2010). Além disso, a taxa de pessoas com TJ no país é similar a outros países nos quais os jogos de azar são legalizados e os jogos 
eletrônicos são uma das principais portas de entrada para a dependência (Medeiros et al., 2016).

\subsection{Diagnóstico}

O TJ foi reconhecido oficialmente como transtorno do comportamento em 1980, com sua inclusão no Diagnostic and Statistical Manual of Mental Disorders - DSM-III (APA, 1980). Na época, a nomenclatura definida foi Jogo Patológico e sua classificação foi inserida na sessão "Transtornos de Controle do Impulso Não Classificados em Outro Lugar”. No DSM-5, a nomenclatura mudou para Transtorno do Jogo e o mesmo foi incluído entre os "Transtornos Relacionados à Substâncias e Adição" (APA, 2013). Essa alteração se deu principalmente devido à correlação entre os jogos de azar e as dependências químicas, no tocante à psicopatologia, comorbidade psiquiátricas, fatores de risco genético e ambientais compartilhados, neurobiologia e abordagem terapêutica (Araujo; Lotufo Neto, 2014).

Para a identificação da presença desse transtorno, segundo o DSM-5 (APA, 2013), deve-se atender quatro ou mais dentre os seguintes critérios abaixo relacionados em um período de 12 meses:

a) Necessidade de apostar quantias de dinheiro cada vez maiores a fim de atingir a excitação desejada;

b) Inquietude ou irritabilidade quando tenta reduzir ou interromper o hábito de jogar;

c) Esforços repetidos e malsucedidos no sentido de controlar, reduzir ou interromper o hábito de jogar;

d) Preocupação frequente com o jogo, apresentando pensamentos persistentes sobre experiências de jogo passadas, avaliando possibilidades ou planejando a quantia a ser apostada - ou seja, pensa em modos de obter dinheiro para jogar;

e) Joga quando sente angústia, impotência, culpa, ansiedade ou depressão;

f) Após perder dinheiro no jogo, geralmente volta no outro dia para recuperar o prejuízo;

g) Mente para esconder a extensão de seu envolvimento com o jogo; 
h) Põe em perigo relacionamentos, emprego e oportunidades importantes por causa da dependência no jogo;

i) Depende de outras pessoas para obter dinheiro a fim de saldar prejuízos financeiros causados pelo jogo.

A Classificação Estatística Internacional de Doenças e Problemas Relacionados à Saúde (ICD-11) também alterou a nomenclatura de Jogo Patológico (código F63.0) para Transtorno do Jogo (código EC50) e descreve o TJ como sendo:

Um padrão de persistente ou recorrente comportamento de jogo, podendo ser online (i.e., jogos pela internet) ou off-line (i.e., presencial), manifestado por: 1) controle prejudicado sobre o controle de jogar (considerando início, frequência, intensidade, duração, término, contexto); 2) aumento na prioridade dada ao jogo sobre outros interesses da vida e atividades diárias; 3) continuação do comportamento de jogar, apesar da ocorrência de consequências negativas; e 4) comprometimento significativo nas áreas pessoais, familiares, sociais, educacionais, ocupacionais ou outras áreas importantes do indivíduo. O padrão do comportamento do jogo pode ser contínuo ou episódico e recorrente por um período de, pelo menos, 12 meses, embora a duração necessária possa ser reduzida se todos os requisitos de diagnóstico forem atendidos e os sintomas forem graves." (WHO, 2018).

O TJ deve ser distinguido de: 1) jogo social, motivado pelo prazer de jogar ou por uma tentativa de ganhar dinheiro, mas refreado face a perdas financeiras significativas ou outros prejuízos decorrentes do jogo; 2) jogo em personalidades maníacas ou sociopáticas, nas quais a dependência do jogo está diretamente relacionada aos prejuízos psíquicos dessas patologias (De Oliveira; Da Silveira; Silva, 2008). Assim, uma pessoa que joga socialmente consegue parar de jogar a qualquer momento, independente de estar ganhando ou perdendo, pois em geral outros aspectos de sua vida são mais importantes que o jogo. No caso dos Portadores de Transtorno do Jogo (PJ), esse controle sobre o jogar não é possível, pois sua autoestima está diretamente relacionada ao fracasso ou sucesso no jogo (Biolcati; Passini; Griffiths, 2015).

\subsection{Epidemiologia}

O TJ afeta entre 0,2 a 5,3\% das pessoas no mundo, embora essa prevalência possa variar de acordo com os instrumentos e métodos de rastreio utilizados, bem como a facilidade de acesso a oportunidades de apostar (Hodgins; Stea; Grant, 2011). Por um 
lado, a idade, a renda per capita e as crenças sobre o poder das próprias habilidades e da sorte são fatores que podem influenciar no comportamento de jogo; por outro lado, o grau de instrução e a consciência quanto às probabilidades de sucesso diminuem a probabilidade de se desenvolver esse comportamento. O TJ tem sido associado com gênero masculino, baixa idade, menos educação e desemprego (Tavares et al., 2010), e apesar de alguns desses estudos mostrarem que pouco mais da metade dos PJ é casada, as taxas de divórcio são mais altas em comparação com a população não-jogadora (Nichols; Stitt; Giacopassi, 2004).

Com relação a gênero, apesar dos homens serem maioria dentre os PJ, há uma parcela importante das mulheres nos grupos mais velhos, demonstrando que o perfil etário da mulher PJ é diferente do perfil masculino (Carneiro et al., 2019). Muitos PJ não identificam o jogo como sendo um problema a ser tratado, pois em muitos casos o TJ vem acompanhado de outras patologias associadas: em estudo realizado em São Paulo com 74 dependentes de álcool e outras drogas em tratamento, constatou-se que $18 \%$ dos farmacodependentes preenchiam critério também para TJ, apesar de não terem mencionado isso como queixa (De Carvalho et al., 2005); dentre os grupos mais jovens, verificou-se uma crescente expansão da dependência de jogo pela internet entre os adolescentes (Nelson et al., 2008).

Apesar de haver evidências do crescimento no número de PJ em conjunto com o aumento da disponibilidade de jogos de azar (incluindo os jogos virtuais), os dados epidemiológicos sobre TJ no Brasil geralmente provêm de estudos com PJ que procuram tratamento (Oliveira; Silveira; Silva, 2008), o que sugere a necessidade de mais iniciativas de órgãos governamentais e entidades no sentido de promover estudos nesse sentido (Carneiro et al., 2014).

\subsection{Comorbidades e relações genéticas e bioquímicas}

O TJ tem alta correlação com dependência de substâncias como álcool e drogas (Tavares; Gentil Filho, 2007; Buja et al., 2017) e frequentemente há associação com outros transtornos psiquiátricos tais como depressão e ideação suicida (Rogier; Picci; Velotti, 2019), transtorno de ansiedade e outros transtornos de humor (Petry; Stinson; Grant, 2005; Nigro; Ciccarelli; Cosenza, 2018). Em estudo para analisar os três grupos com hábitos de jogo (TJ, jogo social e jogo em personalidades psiquiátricas), verificou- 
se que o grupo do TJ possui os maiores índices de comorbidade em comparação aos demais grupos (Parhami et al., 2014).

O jogo estimula alta frequência cardiovascular, com alterações nos hormônios relacionados ao estresse como o cortisol (Krueger; Schedlowski; Meyer, 2005; Wemm et al., 2020), além de alterações diversos sistemas de neurotransmissores - serotoninérgico, dopaminérgico, adrenérgico e opióide (Williams; Potenza, 2008). Alguns estudos (Reuter et al., 2005) também verificaram menor ativação do estriado ventral direito em PJ, além de menor ativação no córtex pré-frontal ventromedial (responsável pela avaliação de riscos) e ventrolateral (relacionado com o controle dos impulsos). Verificou-se também a ativação da região do estriato ventral (núcleo accumbens, responsável pelo sistema de recompensas do cérebro) e da amígdala (principal responsável pelo processamento das emoções e desencadeadora de comportamentos emocionais relacionados ao prazer e ao medo) quando os pacientes viam imagens de pessoas jogando, sugerindo que essas áreas também podem ter um papel importante para o desencadeamento da dependência do jogo (Nestler; Malenka, 2004; Crockford et al., 2005; De Oliveira; Da Silveira; Silva, 2008).

$\mathrm{O}$ TJ tem sido considerado uma dependência comportamental semelhante à dependência química no sentido de que há uma deficiência no sistema mesolímbico de recompensa mediada pela dopamina; assim, o uso de substância ou engajamento nas apostas seria uma tentativa de compensação dessa deficiência (Reuter et al., 2005; Mann et al., 2016).

Alguns estudos sobre padrões de herança genética nos TJ têm mostrado indícios de que há maior ocorrência desse transtorno entre familiares, principalmente gêmeos monozigóticos (Martins et al., 2002). Nesses estudos com gêmeos, sugere-se que uma parte substancial do risco para TJ é herdado, porém fatores ambientais possuem impacto tão significativo no desencadeamento do jogo quanto fatores genéticos comuns (Kim et al., 2017).

\subsection{Avaliação e tratamento}

$\mathrm{Na}$ anamnese, alguns aspectos são importantes para uma avaliação inicial em conjunto com os testes comumente aplicados e definição de um tratamento mais eficaz, por exemplo: tipo de comportamento de jogo (em grupo ou sozinho, tipo de jogo preferido); padrão do comportamento (frequência, horário do dia, locais, tempo 
despendido por dia), consequências pessoais (saúde, situação financeira, legal, familiar e profissional); antecedentes familiares, fatores de risco externos e internos (em que momento mais ocorre o desejo de jogar), consequências obtidas desde o início do transtorno e quais tentativas já feitas para parar de jogar (Otto et al., 2020).

Segundo Rosenthal (1992), há quatro fases do comportamento de jogar:

a) fase da vitória, momento em que a sorte inicial vai sendo rapidamente substituída pela habilidade no jogo e por um otimismo não realista; nessa fase, as vitórias se tornam cada vez mais excitantes, o individuo passa a jogar cada vez mais, os valores apostados vão aumentando progressivamente e a perda passa a ser maior;

b) fase da perda, na qual surge a contração de dívidas e o dinheiro ganho no jogo é utilizado para jogar mais, podendo comprometer todo salário, economias e poupanças. A perda é cada vez mais difícil de ser tolerada e o individuo passa a jogar sozinho; as principais características dessa fase são o aumento de tempo e dinheiro gastos com o jogo, bem como o afastamento da família;

c) fase do desespero, caracterizada pelo estado de pânico no qual o PJ é acometido quando percebe as consequências de seus atos e o tamanho de sua dívida, o desejo de pagá-la prontamente, o isolamento de familiares e amigos, a reputação negativa que passou a ter na sua comunidade e um desejo nostálgico de recuperar os primeiros dias de vitória. Nesse estágio, alguns utilizam recursos ilegais, como furto e falsificação, e é comum o PJ se tornar física e psicologicamente exausto, com depressão e pensamentos suicidas;

d) fase da desesperança, na qual os PJ consideram ter chegado "ao fundo do poço”. Nessa fase, muitos consideram que ninguém mais se importa com eles e que a recuperação pode ser impossível. Em alguns casos, aparece o abuso de álcool e drogas, bem como pensamentos autodestrutivos e tentativas de suicídio.

Em programas de suporte e orientação de jogadores, considera-se a existência de uma $5^{\text {a }}$ fase, a fase de recuperação (Grant; Potenza, 2008), na qual o PJ admite que tem um problema e busca a abstinência e o apoio profissional. Os principais tratamentos para TJ incluem psicoterapia e terapia familiar, grupos de autoajuda como os JA - Jogadores Anônimos (McGrath et al., 2018) e intervenção farmacológica, importante principalmente para tratamento das comorbidades associadas (Hodgins; Stea; Grant, 
2011). Os tratamentos realizados com equipe multidisciplinar aqui são essenciais, uma vez que terapias combinadas promovem a remissão dos sintomas e prevenção de recaídas.

Durante o processo terapêutico, o esclarecimento sobre o TJ para pacientes e familiares é fundamental, bem como estimular o engajamento de ambos para um tratamento eficaz (Archer et al., 2019). Além disso, é importante identificar os principais precipitantes de uma eventual recaída, tais como estados emocionais negativos ou autodestrutivos que geralmente surgem antes ou no momento da ocorrência do primeiro lapso; conflitos interpessoais (maritais, familiares, profissionais ou com amigos); tentativas de testar a própria capacidade de controle (testes de "força de vontade"); crises de avidez (do inglês craving) ou fissura (como é coloquialmente relatado pelos pacientes) que ocorrem especialmente em situações na qual não há acompanhamento profissional para o TJ ou para as comorbidade associadas; e pressão social de pessoas ou grupos com os quais o paciente compartilhava os momentos de jogo (Aragay et al., 2015).

Os programas de tratamento e prevenção da recaída focam também na mudança de hábitos, desmistificação das crenças irracionais associadas ao jogo de azar e estabelecimento de atividades prazerosas alternativas (Magalhaes et al., 2009).

\subsection{Desamparo aprendido, ilusão de controle e superstição}

O desejo de controle está geralmente presente, em maior ou menor grau, nos seres humanos (Goodie, 2003; Cantinotti; Ladouceur; Jacques, 2004), e em algumas condições pode ser altamente adaptativo, pois muitas vezes não sabemos quando um evento pode ser controlável ou não (Gibson; Sanbonmatsu, 2004; Wohl; Enzle, 2002). Portanto, a tentativa de controle nos auxilia a buscar indicativos para lidar com o ambiente. Quando esse controle é ameaçado ou perdido, há uma tentativa de protegê-lo ou recuperá-lo, por exemplo, por meio da repetição de estratégias que foram bem sucedidas em situações semelhantes anteriores (Aragay et al., 2015). A falha em exercer esse controle ou em readquiri-lo gera o desamparo aprendido, que é a crença de que não é possível controlar o que acontece à nossa volta (Hunziker, 2003; Samelo, 2012). O desamparo aprendido, quando exacerbado, gera um efeito deletério e resulta na depressão; entretanto, sua instalação em contexto apropriado previne que o indivíduo siga investindo energia em tarefas inócuas ou deletérias (Abreu, 2011; Ferreira; Tourinho, 2013).

Uma pesquisa feita por Hiroto e Seligman (1975) para analisar o desamparo 
aprendido utilizou um teste de análise de resposta-consequência com reforço negativo intermitente seguido de um feedback de erro. Nesse estudo, os voluntários eram instruídos a tentar controlar um ruído irritante digitando uma sequência de dois dentre três dígitos possíveis. Havia duas versões do teste: uma com solução, ou seja, o ruído poderia ser interrompido com a digitação de uma sequência numérica a ser descoberta; e uma versão sem solução, na qual o ruído era interrompido em intervalos variados, independente da sequência digitada (portanto, o teste não tinha solução). Na segunda versão, cada vez que uma sequência era digitada, uma luz vermelha acendia indicando que esta não era a sequência correta. Após algum tempo de teste, os participantes da versão sem solução deixavam de responder ativamente e entravam em desamparo aprendido.

Baseada nesse experimento, Matute $(1994,1995)$ desenvolveu pesquisas cujo objetivo era verificar o efeito de testes de análise de resposta-consequência com e sem solução, porém sem o feedback de erro utilizado por Hiroto e Seligman (1975). Os resultados mostraram que sujeitos privados de feedback de erro não entravam em desamparo, mas tinham maior chance de desenvolver superstições e ilusão de controle frente a um teste sem solução. Com isso, Matute (1994) concluiu que a ilusão de controle se relaciona mais diretamente com situações em que somos orientados a buscar algum benefício ou segurança por meio do controle do ambiente. De fato, quando a instrução de um teste de análise resposta-consequência é modificada e o participante é solicitado a ganhar ou a encontrar uma solução, o indivíduo tende a ignorar o retorno de falha e a ilusão de controle aumenta. Por outro lado, a ilusão não acontece (ou acontece com menor probabilidade) quando o indivíduo é solicitado a avaliar a controlabilidade de um dado evento, quando há a ausência de reforçamento (extinção), alto custo de resposta, punição severa ou fadiga do participante (Matute, 1996).

A ilusão de controle é um fenômeno inicialmente descrito por Langer (1975) e definido como a tendência a perceber que uma habilidade pessoal pode influenciar consequências que são obviamente determinadas de forma aleatória, por sorte; é uma dificuldade em discernir eventos controláveis de eventos incontroláveis (Wohl; Enzle, 2002; Cantinotti; Ladouceur; Jacques, 2004). Existem alguns fatores que tornam mais forte a ilusão de controle além das questões individuais, tais como: familiaridade da tarefa, grau de motivação ou estresse, envolvimento pessoal com a tarefa (ativo ou passivo), custo de resposta e extensão das possibilidades de escolha (Matute, 1994, 1996; Makridakis; Moleskis, 2015). Por outro lado, quanto maior o número de tentativas em 
uma determinada situação e maior o tempo de exposição a um dado evento, menor a ilusão de controle, mesmo quanto há envolvimento pessoal e ativo (Perales et al., 2017).

Assim, a ilusão de controle pode ser compreendida como uma forma de proteger a autoestima, promovendo um tipo de aversão ao fracasso. Nesse sentido, indivíduos com alta autoestima são mais receptivos a feedback positivo e menos receptivos a feedback negativo em relação aos indivíduos com baixa autoestima, subestimando inclusive a quantidade de feedback negativo que recebem. Já os indivíduos mais ansiosos e menos confiantes atribuem eventos negativos a causas internas, arriscam-se menos e desenvolvem menos ilusão de controle (Goodie, 2003; Gibson; Sanbonmatsu, 2004).

No caso do TJ, a literatura empírica identificou muitos fatores de risco que podem contribuir para o desenvolvimento desse transtorno, dentre eles as distorções cognitivas (Fauth-Bühler; Mann; Potenza, 2017). Especificamente, a ilusão de controle, a sensação de que alguém pode influenciar um resultado aleatório, foi sugerida como um fator que aumenta o risco de desenvolver o vício em jogos de azar, em comparação com indivíduos sem essa condição (Wohl; Enzle, 2002, Myrseth; Brunborg; Eidem, 2010). Dentre as distorções cognitivas sobre jogo estão as crenças infundadas que atuam como fator mantenedor das apostas. Elas são de dois tipos (Steenbergh et al., 2002):

a) Tipo 1: associadas à crença na sorte e na necessidade de persistir: "se eu continuar, uma hora meu esforço será recompensado"

b) Tipo 2: ilusão de controle e negação da independência dos eventos, o que favorece a crença na capacidade de prever e influenciar o resultado do jogo.

A sorte, para os PJ, é tratada como uma instância passível de controle por meio de rituais e comportamentos padronizados pelo próprio indivíduo, independente do ambiente no qual esteja (Wohl; Enzle, 2002). Os rituais executados durante as apostas com a finalidade de trazer sorte podem ser compreendidos como comportamentos supersticiosos, ou seja, atitudes arbitrárias e irracionais que são conduzidas como se tivessem alguma relação ou poder de influência sobre o resultado do jogo (Myrseth; Brunborg; Eidem, 2010). Esse comportamento se torna condicionado quando há uma ordem e proximidade temporal acidental entre resposta e consequência, o que faz com que um determinado comportamento persista mesmo sem realmente ter qualquer função vantajosa para se obter o resultado desejado (Joukhador; Blaszczynski; Maccallum, 2004, Perales et al., 2017). Assim, podemos ver a necessidade de alguns PJ em escolher sempre um determinado número (ou sequência de números) ou em usar determinada roupa ou 
mesmo executar certos movimentos que, para o PJ, garantem maior chance de vitória porque possivelmente estavam presentes alguma vez quando aquele PJ ganhou (ou viu alguém ganhar) uma aposta.

O comportamento supersticioso está presente nos PJ de forma sistemática em comparação com a população não-jogadora (Fong; Lam; Fong, 2018). Ou seja, em PJ há a expressão recorrente de certos padrões supersticiosos, diferentemente da população não-jogadora, na qual não há uso específico de padrões supersticiosos para se obter uma vitória em jogos de azar. Além disso, a superstição em PJ está presente em diversas culturas: em um estudo sobre comportamentos supersticiosos com 323 PJ de diferentes nacionalidades (Kim et al., 2016), incluindo americanos, chineses, japoneses e coreanos, verificou-se que o comportamento supersticioso, embora exacerbado entre os americanos em comparação com os demais grupos, está presente em praticamente todos os casos de forma mais ou menos similar.

No fenômeno da "falácia do jogador", há a crença de que sequências randômicas (como o lançamento de dados ou de uma moeda) exibindo o mesmo resultado consecutivamente serão interrompidas por uma consequência oposta, sem considerar a independência entre os eventos (Matarazzo et al., 2019). Ou seja, na falácia do jogador há a crença de que ocorrências passadas interferem nas chances de sucesso futuras, ainda que os eventos sejam independentes entre si. Apostar em animais, torneios esportivos ou corridas com veículos automotivos, por exemplo, dão a falsa impressão de que é possível prever um resultado a partir do conhecimento sobre o desempenho histórico e atual que se tem sobre a situação das equipes e dos animais, mesmo que ao fim o número de ganhos não seja maior do que o número de ganhos em escolhas feitas ao acaso (Cantinotti; Ladouceur; Jacques, 2004).

Fazer análises e tentar prever o futuro com base nelas é uma característica humana, porém o apostador é aquele indivíduo que, imbuído de uma convicção extraordinária, arrisca empenhar um valor financeiro em sua previsão (Toneatto, 1999). Além disso, quando o apostador tem a possibilidade de fazer escolhas durante uma aposta, tais como o número a ser apostado e o local onde apostar, registrar e pagar eles mesmos, todas essas opções aumentam a percepção de controlabilidade, mesmo que nesses casos o efeito sobre o resultado da aposta também seja rigorosamente nulo (Tobias-Webb et al., 2017). Em estudo com duas versões de um simulador de caça-níqueis, um com um botão de parada e outro sem um botão de parada, a presença do botão de parada gerava mais 
cognições errôneas (13.6\%) e quase-erros (16\%), e os PJ tinham SCRs maiores para todos os resultados, sugerindo que o botão incentivava uma percepção errônea de habilidade e, consequentemente, afetava a forma como esses PJ percebiam seus resultados em jogos (Dixon et al., 2018). Portanto, em situações em que os PJ são solicitados a ganhar mesmo quando os resultados são incontroláveis, os indivíduos têm a tendência a se comportar como se eles estivessem numa situação que requer habilidade, e incorretamente passam a perceber a situação como controlável e, mais do que isso, que são capazes de exercer o controle da própria sorte intencionalmente (Wohl; Enzle, 2002).

Duas características do TJ que possuem direta correlação com os comportamentos supersticiosos são a persistência do jogo apesar dos prejuízos e o aumento da frequência mesmo frente a qualquer consequência social adversa (Fauth-Bühler; Mann; Potenza, 2017). Ainda não se sabe o que mantém esses comportamentos: além das questões de herança genética (Martins et al., 2002), existem hipóteses relacionadas ao desejo psicanalítico inconsciente (sadomasoquista) de punir a si mesmo (Rosenthal, 2015), o comportamento baseado em reforçamento intermitente (Orgaz; Estevez; Matute, 2013) e as distorções cognitivas (Barrault; Varescon, 2013). Outras hipóteses como reprodução de comportamentos familiares, busca de excitação ou prazer e fuga de problemas também são amplamente contempladas (Delfabbro, 2004).

Diversão e motivação financeira podem explicar a decisão inicial de jogar (Rogier; Picci; Velotti, 2019; Eysop et al., 2019); porém, à medida que progride o compromisso com a atividade, o PJ desenvolve crenças e rituais supersticiosos, muitas vezes estereotipados, sedimentados pela experiência acumulada em sucessivas apostas. A dificuldade em perceber a inutilidade de tentar controlar eventos aleatórios se verifica no cotidiano dos PJ, quando eles procuram o jogo como uma solução para sanar dívidas que o próprio jogo causou. Premidos pela necessidade, eles se voltam mais para obtenção de um resultado do que para compreensão do que se passa no jogo, o que os impede de fazer a leitura apropriada dos sinais de falha de controle, previne o desamparo aprendido e permite a continuidade do jogo (Wiehler; Peters, 2015). Eventualmente alguma tentativa de obter um resultado favorável será aleatoriamente reforçada e assim se desenvolvem as distorções cognitivas e a ilusão de controle (Lorains et al., 2014).

A ilusão de controle responde pela persistência das apostas mesmo diante de prejuízos financeiros e sociais, e nos PJ a ilusão de controle aumenta quando as vitórias acontecem seguidamente e no começo, em comparação com aqueles que terminam 
ganhando ou ganham randomicamente (Perales et al., 2017; Dixon et al., 2018). Embora o jogo permita uma oportunidade de obter ganhos substanciais, são necessários investimentos que geralmente resultam em déficits monetários, e então o PJ é mais um perdedor que um ganhador (Joukhador; Blaszczynski; Maccallum, 2004, Cowie et al, 2017).

A percepção quanto às chances de vitória considera a presença de dois sistemas de processamento de informação que operam juntos: um baseado na racionalidade e outro mais emocional, baseado nas experiências anteriores. Eles variam de acordo com o grau de envolvimento pessoal e são afetados pelo nível de percepção de recompensa ou frustração que cada situação provoca: assim, numa situação que oferece consequências positivas, os comportamentos trazidos à tona são mais intuitivos, com um responder mais passivo e otimista; já nas situações que oferecem consequências negativas, os comportamentos trazidos são mais racionais e com o desencadeamento de traços de memória que ajudam o indivíduo a responder adequadamente, sugerindo que a ilusão de controle acontece mais em atividades com ganhos do que em atividades com perdas (Kruglanski; Gigerenzer, 2011). No caso dos PJ, a predisposição a superestimar as contingências positivas gera a crença de que certos resultados, mesmo arbitrários, não podem ser casuais devido à sua configuração (Boynton, 2003): em um estudo de Benhsain, Taillefer e Ladouceur (2004), percebeu-se que apesar da frequência das distorções cognitivas e do comportamento de jogo diminuir quando os PJ descreviam em voz alta suas análises e seus resultados positivos ou negativos, ainda se observou a presença de muitas falsas crenças e a dificuldade de percepção de casualidade.

Orgaz, Estevez e Matute (2013) usaram uma tarefa de aprendizado associativo padrão para avaliar o aparecimento de ilusão de controle em PJ: em seu estudo, os participantes foram convidados a imaginar um médico que usava um medicamento experimental que poderia curar crises dolorosas produzidas por uma doença fictícia. Eles também foram informados de que a eficácia desse medicamento experimental não havia sido comprovada e que poderia produzir efeitos secundários, de modo que eles tiveram que escolher cuidadosamente ao usá-lo. Os participantes foram expostos aos registros de 100 ensaios, nos quais os participantes poderiam optar por dar ou não dar esse medicamento experimental ao paciente. O software mostrou se o paciente fictício superou a crise ou não, e após os 100 ensaios de treinamento, os participantes foram solicitados a avaliar a eficácia do medicamento experimental na cura das crises. Os resultados 
mostraram que a ilusão era significativamente mais forte nos PJ do que nos $\mathrm{CN}$, ou seja, os PJ consideraram que o medicamento hipotético funcionou melhor quando eles escolheram quem o tomaria, mesmo que o resultado fosse gerado aleatoriamente, mostrando uma relação entre essas medidas objetivas de ilusão de controle e o TJ. No entanto, essas medidas não podem revelar se a ilusão de controle é um fator de risco preexistente ou se é um subproduto do jogo frequente.

Embora a ligação entre a ilusão de controle e o TJ esteja sendo estabelecida, a literatura ainda apresenta algumas limitações metodológicas, pois grande parte da pesquisa existente sobre ilusão de controle é aplicada e medida com base em autorrelatos (Perales et al., 2017). Outro limitante é que a maioria dos paradigmas comportamentais envolvem tarefas que simulam apostas, portanto remetem o PJ para um contexto no qual ele já está previamente sensibilizado e com respostas já consolidadas.

A relação entre apostar e a as modalidades de reforçamento positivo, negativo e punição no jogo de azar é paradoxal, pois ao mesmo em que o TJ é uma atividade prazerosa e habitual, a longo prazo traz danos que teoricamente justificariam a interrupção do comportamento e o desamparo aprendido. O desenvolvimento de superstições, ilusão de controle ou falha na percepção dos sinais de erro poderiam ser explicações que o trabalho atual se propõs a investigar em seus dois estudos.

No primeiro estudo (piloto), a proposta foi testar o paradigma de Matute (1994) numa versão com feedback de erro para avaliar a ilusão de controle e qualquer outro fenômeno que possa precedê-lo (como as distorções cognitivas e o desamparo aprendido). Aqui utilizamos dois tipos de Teste Curto de Análise de Resposta-Consequência (TCARC): no primeiro TCARC o estímulo aversivo poderia ser interrompido por meio da digitação de uma senha (condição controlável); e no segundo TCARC os participantes precisavam detectar a impossibilidade de controle com base na comparação com o teste controlável. Teorizamos que ensaios curtos com feedback de erro poderiam auxiliar na identificação de respostas cognitivas, afetivas e comportamentais precoces em PJ, as quais quando aleatoriamente reforçadas poderiam levar a estratégias subótimas, distorções cognitivas e ilusão de controle.

No segundo estudo (principal), a proposta foi testar o paradigma de Hiroto e Seligman (1975) em quatro novos subgrupos de PJ e CN, porém mantendo uma quantidade maior de tentativas (50 tentativas) como no estudo de referência, no intuito de verificar as semelhanças e diferenças entre as respostas do estudo piloto e no estudo 
principal.

Assim, a proposta foi testar se os PJ teriam maior probabilidade de desenvolver ilusão de controle por meio de um paradigma com o qual eles provavelmente não estão familiarizados, de modo a avaliar como a ilusão de controle (ou o desamparo aprendido) se desenvolve após exposição repetida à tarefa. Para ter sucesso nos dois testes, o participante precisava aplicar uma estratégia combinatória e reconhecer as emoções negativas geradas pelo feedback de falha. Nossa hipótese foi que, devido a falhas consecutivas, os participantes considerariam a versão incontrolável mais emocionalmente angustiante, o que por sua vez levaria a uma maior incerteza sobre a capacidade de controlar o estímulo aversivo, menor probabilidade em usar uma estratégia combinatória e, com isso, os participantes iriam apresentar desempenho reduzido em relação ao TCARC e ao Teste Longo de Análise de Resposta-Consequência (TLARC) controlável.

Também hipotetizamos que os PJ teriam respostas emocionais significativamente diferentes em comparação aos CN: especificamente, os PJ ficariam mais ansiosos para encontrar o código, mas dada a sua propensão à ilusão de controle, ficariam mais confiantes sobre isso quando encontrassem uma resposta, certa ou errada. A TJ tem sido associada ao transtorno do déficit de atenção e hiperatividade (TDAH), memória de trabalho e comprometimento das funções executivas (Marazziti et al., 2008), levando-nos à hipótese de que os PJ teriam dificuldade na aplicação de estratégias combinatórias. Por fim, com base em estudos anteriores (Orgaz; Estevez; Matute, 2013), hipotetizamos que comportamentos supersticiosos seriam mais comuns nos PJ do que em $\mathrm{CN}$. 
2. OBJETIVOS 


\section{OBJETIVOS}

\subsection{Objetivo geral}

Comparar o desempenho de PJ e CN frente a um TCARC ou TLARC em duas versões, com solução (CS) e sem solução (SS), em sequências alternadas (CS-SS e SS$\mathrm{CS})$.

\subsection{Objetivos específicos}

Na comparação entre testes:

1) Verificar a ocorrência de variáveis afetivas (ansiedade, felicidade e confiança) na investigação da solução no TCARC e TLARC;

2) Verificar a ocorrência do desamparo aprendido em tarefas CS e SS no TCARC e TLARC;

3) Verificar a ocorrência de variáveis comportamentais (superstição, digitação aleatória e quantidade de digitação), na investigação da solução no TCARC e TLARC;

4) Verificar a ocorrência da ilusão de controle em tarefas CS e SS no TCARC e TLARC;

5) Verificar a ocorrência de variáveis cognitivas (uso de estratégia com sequência combinatória; percepção de controlabilidade e crença na resposta) no TCARC e TLARC;

Na comparação entre grupos:

6) Verificar a ocorrência de variáveis afetivas (ansiedade, felicidade e confiança) na investigação da solução em PJ e CN;

7) Verificar a ocorrência do desamparo aprendido em tarefas CS e SS em PJ e CN;

8) Verificar a ocorrência de variáveis comportamentais (superstição, digitação aleatória e quantidade de digitação), na investigação da solução em PJ e CN;

9) Verificar a ocorrência da ilusão de controle em tarefas CS e SS em PJ e CN;

10) Verificar a ocorrência de variáveis cognitivas (uso de estratégia com sequência combinatória; percepção de controlabilidade e crença na resposta) em PJ e CN. 
3. HIPÓTESES 


\section{HIPÓTESES}

Na comparação entre testes:

1) A variável afetiva ansiedade será mais frequente na versão SS do que na versão $\mathrm{CS}$ em ambos os testes, enquanto que as variáveis afetivas felicidade e confiança serão mais frequentes na versão CS em ambos os testes;

2) O desamparo aprendido frente a uma tarefa analítica será mais frequente na versão SS do que na versão CS em ambos os testes;

3) As variáveis comportamentais (superstição, digitação aleatória e quantidade de digitação) serão mais frequentes na versão SS do que na versão CS em ambos os testes;

4) A ilusão de controle frente a uma tarefa analítica será mais frequente na versão SS do que na versão CS em ambos os testes;

5) As variáveis cognitivas (uso de estratégia com sequência combinatória de 2 dígitos; percepção de controlabilidade de cada teste e crença na resposta) serão mais frequentes na versão CS em ambos os testes;

Na comparação entre grupos:

6) A variável afetiva ansiedade será mais elevada em $\mathrm{PJ}$ do que em $\mathrm{CN}$, enquanto que as variáveis afetivas felicidade e confiança serão mais elevadas em $\mathrm{CN}$ do que em PJ;

7) O desamparo aprendido na tarefa analítica sem solução será menos frequente em PJ do que em CN na versão SS;

8) As variáveis comportamentais (superstição, digitação aleatória e quantidade de digitação) serão mais frequente em PJ do que em CN em ambas as versões;

9) A ilusão de controle será mais frequente em PJ do que em CN na versão SS;

10) $\mathrm{O}$ intento de uso de estratégia cognitiva será mais frequente em $\mathrm{CN}$ do que em PJ em ambas as versões. 
4. MATERIAL E MÉTODO 


\section{MATERIAL E MÉTODO}

\subsection{Estudo 1 - piloto}

\subsubsection{Amostra}

PJ: uma amostra de 20 indivíduos foram recrutados no Programa para Tratamento de Jogo (PRO-AMJO) no HC-IPq-FMUSP, de acordo com os seguintes pré-requisitos: 1) preenchimento dos critérios diagnósticos para TJ segundo DSM-5 (APA, 2013), (2) sem comorbidades psiquiátricas e (3) sem uso de medicação no momento da avaliação. Informações adicionais sobre comportamentos de jogo foram coletadas por meio de um questionário semiestruturado que perguntou sobre a idade do início regular do jogo e o tipo de jogo preferido (Tavares et al., 2001) e outros transtornos psiquiátricos importantes foram descartados usando o MINI - Entrevista Neuropsiquiátrica Internacional (Amorim, 2000).

$\underline{\mathrm{CN}}$ : 20 indivíduos, pareados por sexo e idade com o grupo acima, foram recrutados em espaços públicos (estacionamentos, pontos de ônibus etc.) no mesmo bairro do programa de tratamento PRO-AMJO. Os diagnósticos psiquiátricos foram descartados usando um procedimento de duas etapas: primeiro, os participantes preencheram o questionário de autorrelato - SRQ (Barreto Do Carmo et al., 2017) para avaliar distúrbios psiquiátricos, com uma pontuação igual ou superior a 5 (se masculino) ou 7 (se feminino) como indicativo de provável transtorno psiquiátrico. Em seguida, os participantes cujas pontuações não indicaram um transtorno psiquiátrico foram avaliados posteriormente através da Entrevista de Avaliação Clínica em Neuropsiquiatria - SCAN (Schützwohl; Kallert; Jurjanz, 2007). Como nem o SRQ nem o SCAN incluíam avaliação específica para jogos de azar, o diagnóstico de TJ foi descartado com base no questionário Lie/Bet, um rastreio de dois itens para TJ (Johnson; Hamer; Nora, 1998) baseados nos critérios \#1 e \#7 do DSM-5: perda de controle sobre apostas e mentir para familiares e amigos sobre a extensão do seu envolvimento com jogos de azar. Uma resposta positiva a pelo menos um desses itens indicaria um possível problema no jogo, com uma sensibilidade relatada de $99 \%$ e $91 \%$ de especificidade. Para verificar se nenhum controle havia jogado regularmente no ano anterior à pesquisa e nunca teve um problema 
relacionado ao jogo, os que passaram por triagem foram questionados se já haviam jogado mais de três vezes por ano em algum momento de suas vidas. Verificamos que a maioria dos participantes do grupo $\mathrm{CN}$ nunca desenvolveu $\mathrm{TJ}$, e para o pequeno número de participantes que se envolveram em jogos de azar, eles o fizeram esporadicamente (por exemplo, apostando no sorteio especial da loteria da véspera de Ano Novo).

\subsubsection{Procedimento}

Todos os participantes receberam informações gerais sobre a tarefa e um consentimento informado por escrito (TCLE) foi obtido de todos os participantes. Os PJ realizaram a tarefa no Ambulatório de Transtorno do Jogo, enquanto que os participantes do grupo $\mathrm{CN}$ já triados também foram levados ao Ambulatório de Jogos de Azar para uma sala privada e silenciosa; porém, quando não era possível deslocá-los até o ambulatório, os mesmos eram encaminhados para uma sala particular alugada perto do participante, onde a entrevista poderia ser realizada. Após o preenchimento de um questionário de dados sócio-demográfico (QDSD), os participantes eram colocados em frente a um computador. Após ouvirem as instruções para o TCARC (descrito abaixo), era iniciada a atividade nesse computador. Por fim, os participantes preenchiam um questionário auto-aplicável, incluindo perguntas cognitivas e afetivas relacionadas à cada versão do TCARC. A tarefa completa, incluindo a atividade no computador e o preenchimento do questionário, tinham duração de 15-20 minutos.

\subsubsection{Questionário de Dados Sócio-Demográficos (QDSD)}

Trata-se de uma entrevista semiestruturada para investigação de perfil demográfico e informações do histórico clínico do paciente, baseada no modelo da PNAD do IBGE (1998). As seguintes variáveis sócio-demográficas são registradas: gênero, idade, etnia, local de nascimento, estado civil, anos de educação formal, situação profissional, renda familiar média mensal, número de habitantes no domicílio, indicador socioeconômico, afiliação, prática e frequência religiosa. 


\subsubsection{TCARC}

Foi utilizado um programa de computador para produzir um ruído aversivo de $5000 \mathrm{~Hz}(80 \mathrm{~dB})$, com duração máxima de 5 segundos e acionado repetidamente em intervalos de 5 segundos. Esse programa possui duas etapas, ambas com feedback de erro: uma em que a interrupção do som não é possível, e outra em que a interrupção do som é possível. Foram permitidas 10 tentativas em cada versão, sendo que poderiam começar pelo teste com solução (CS) e depois realizar o teste sem solução (SS), ou fazer a sequência inversa. As instruções para as duas versões eram idênticas, ou seja, os participantes eram informados que o computador produziria uma campainha irritante, e o objetivo da tarefa era descobrir se o teste seria controlável e, caso positivo, qual a combinação de dois números entre 1 e 3 (por exemplo, 11, 21, 31 etc.) para parar o barulho. Os participantes tiveram a oportunidade de fazer perguntas e, depois de todos os esclarecimentos, o software era iniciado. Na versão CS, o ruído poderia ser interrompido digitando 31. Todas as digitações feitas durante cada versão foram registradas automaticamente no computador para cada indivíduo.

A seguinte instrução era apresentada: “As únicas teclas válidas no teclado do computador são as teclas 1, 2 e 3. De tempos em tempos, um ruído alto vai tocar por um certo tempo. Tente encontrar uma maneira de interrompê-lo se você acreditar que há alguma forma; ou seja, você pode digitar um número ou não fazer nada. Se a sua escolha for a primeira, o número poderá ter um ou dois dígitos (1, 21, 32, 22, 13 etc), e você deverá tentar interromper a maior parte dos ruídos que conseguir e o mais rápido que puder. Por outro lado, caso você acredite que não há solução para o teste, espere o teste acabar sem fazer nada. Enquanto o ruido estiver tocando, você pode tentar todas as possibilidades que conseguir. Os ruídos têm uma duração máxima de 5 segundos. Assim que estiver preparado (a), pode começar".

As condições de aplicação foram equilibradas de modo que metade dos PJ e CN pareados começassem pela versão SS e, em seguida, pela versão CS, e a outra metade de ambos os grupos fizesse a sequência inversa.

\subsubsection{Questionário pós-teste}

Após a etapa no computador, foi aplicado um questionário pós-teste para verificar, 
dentre outras informações, as variáveis cognitivas e afetivas decorrentes de cada teste, e qual a análise do participante na comparação entre os dois testes executados (CS-SS ou SS-CS). Essas medidas (descritas abaixo, no item 4.1.3), juntamente com as medidas comportamentais obtidas na análise da digitação, serviram de base para a análise dos objetivos propostos.

\subsubsection{Medidas}

1) Variáveis Afetivas: escalas visuo-analógicas foram usadas para avaliar três emoções: ansiedade, felicidade e confiança, numa escala de $10 \mathrm{~mm}$ com distribuição de 0 a 3 (de "Nenhuma" a "Extremamente") (Bond; Lader, 1974).

2) Variáveis comportamentais: três variáveis foram derivadas dos registros do computador: a) número total dígitos por teste - ou seja, quantos números foram digitados por teste; b) tipo de estratégia (padrão de digitação combinatório ou aleatório) - as respostas eram consideradas 0 se um padrão de digitação fosse identificado (sugerindo uma sequência combinatória, i.e., 11, 22, 33, 12, 13... ou $12,21,13,31,23,32$, etc.) ou a estratégia foi considerada 1 se as respostas fossem identificadas como randomizadas (nenhum padrão de digitação identificada); c) comportamento supersticioso: se houve uma senha específica (diferente de 31 para a versão CS ou qualquer senha para a versão SS) que foi falsamente identificada como sendo a solução, pois foi digitada três vezes ou mais em sequência.

3) Variáveis cognitivas: cinco perguntas foram consideradas para avaliar as estratégias cognitivas: a) uma pergunta aberta sobre o que o participante fez durante cada teste para tentar controlar os ruídos, sendo as respostas posteriormente classificadas em 1 - "seguiu uma estratégia específica" e 0 "apenas digitou aleatoriamente os números"; b) porcentagem de ruídos que eles acreditavam terem sido controlados; c) se havia uma senha para interromper o ruído; d) grau de certeza sobre a resposta; e) qual era o código correto.

Os dados registrados no computador foram posteriormente analisados por dois avaliadores que não tiveram acesso à condição do participante $(\mathrm{PJ}$ ou $\mathrm{CN})$ e a qual sequência faziam parte (CS-SS ou SS-CS). A classificação do padrão de digitação foi 
estabelecido de forma independente pelos dois autores do estudo, o nível de concordância foi de $70 \%$ e os casos em desacordo $(n=12)$ foram reexaminados e reclassificados por consenso entre os avaliadores; c) comportamento supersticioso, caso houvesse uma combinação digitada mais de 3 vezes em sequência, diferente da senha 31 na condição controlável ou qualquer uma na condição incontrolável.

\subsubsection{Considerações Éticas}

O estudo piloto foi submetido para análise para o comitê de ética do HC-FMUSP, de acordo com as orientações e princípios da Declaracão de Helsinque da Associação Médica Mundial (1997).

\subsubsection{Análise estatística}

Os resultados analisados tiveram o nível significância estabelecido em 5\% $(\mathrm{p}<0,05)$. Para a análise de dados, utilizamos o programa SPSS (1989-2019), versão 18.

Primeiro, realizamos uma análise das variáveis sócio-demográficas de todos os sujeitos, depois realizamos uma comparação com base na diferenciação de diagnóstico (PJ ou CN). Também contrastamos o desempenho dos participantes entre as duas versões de teste (CS e SS), a fim de examinar a confiabilidade do paradigma. Para dados contínuos, usamos o teste de $t$ de Student pareado ou o Wilcoxon e para variáveis categóricas usamos o McNemar test. Na sequência, comparamos o desempenho dos participantes de acordo com o diagnóstico (PJ ou CN) nos testes $\mathrm{CS}$ e SS, levando em consideração as variáveis afetivas e cognitivas relatadas no questionário pós-teste, e as variáveis comportamentais consideradas na análise das digitações registradas no computador. Para isso, utilizamos os testes $t$ de Student ou o $U$ de Mann-Whitney para variáveis contínuas, e Qui-Square para variáveis categóricas. Por fim, comparamos as respostas referentes a uso de estratégia no questionário pós-teste com os comportamentos registrados no computador, classificando as respostas em: 1) o entrevistado relatou usar uma estratégia para encontrar a combinação e identificamos a estratégia em seus dígitos; 2) o entrevistado não relatou usar uma estratégia para encontrar a combinação e não identificamos uma estratégia em seus dígitos; 3 ) o entrevistado relatou usar uma estratégia para encontrar combinações, mas não identificamos uma estratégia em seus dígitos (Erro 
1); 4) o entrevistado não relatou usar uma estratégia para encontrar a combinação, mas identificamos a estratégia em seus dígitos (Erro 2).

Depois, realizamos uma regressão logística para comparar o desempenho de PJ e $\mathrm{CN}$ em relação às variáveis demográficas, afetivas, comportamentais e cognitivas que se aproximaram da significância $\mathrm{p}<0,10$ na etapa da análise univariada dos dados. Também comparamos o desempenho nas duas versões do TCARC em relação ao gênero (Feminino ou Masculino) e à sequência de testes (CS-SS ou SS-CS) para controlar possíveis vieses.

\subsection{Estudo 2 - principal}

\subsubsection{Amostra}

Para ambos os grupos, consideraram-se como critérios de inclusão os mesmos já estabelecidos no estudo piloto. Para os critérios de exclusão, consideramos somente os participantes $(\mathrm{PJ}$ ou $\mathrm{CN}$ ) que apresentaram patologia clínica que demandasse atendimento emergencial em caráter de internação em outro serviço, portadores de retardo mental, ou afecção no sistema nervoso central, com prejuízo grave das funções cognitivas, portadores de transtorno psicótico que pudesse comprometer as respostas às escalas em uso, e os participantes que desistiram de encontrar a senha e se recusaram a permanecer em frente ao computador e ouvindo os ruídos até o término das repetições.

1) PJ: a amostra se constituiu de indivíduos que preencheram os critérios diagnósticos conforme já estabelecido no estudo piloto. Além disso, em caso de uso de qualquer medicação, o paciente deveria apresentar prescrição estável, ou seja, sem introdução de novos fármacos ou alteração de dosagem por pelo menos quatro semanas. $\mathrm{O}$ teste foi aplicado durante o período de triagem para inclusão nos grupos de tratamento do PRO-AMJO.

2) $\mathrm{CN}$ : a coleta desse grupo foi feita posteriormente à coleta dos $\mathrm{PG}$, considerandose os mesmos critérios do estudo piloto.

\subsubsection{Procedimento}

O procedimento se constituiu dos mesmos critérios já estabelecidos no estudo 
piloto, sendo que a única diferença foi que, diferentemente do estudo piloto, o estudo principal contou com 50 tentativas (40 tentativas a mais em relação ao estudo piloto).

\subsubsection{Medidas}

Assim como no estudo piloto, para avaliação das variáveis de desfecho primário (ilusão de controle e desamparo aprendido) e desfecho secundário (crença na existência de uma solução para cada etapa do teste, convicção desta crença, sensação de controle sobre o teste, ansiedade, felicidade, auto-confiança), dividimos as análises em medidas afetivas, comportamentais e cognitivas. As variáveis afetivas consideradas esse segundo estudo foram as mesmas do estudo piloto.

Nas variáveis comportamentais, além das variáveis já consideradas no estudo piloto também consideramos: 1) Padrão de digitação (Ausente, ou seja, com digitação aleatória; Parcial I, ou seja, a digitação aleatória predomina sobre a digitação combinatória; Parcial II, ou seja, a digitação combinatória predomina sobre a digitação aleatória; e Completo, ou seja, com uso consistente de estratégia combinatória, com todas as opções de combinação dois a dois sendo sequencialmente testadas - 11, 12, 13, 21, 22, 23, etc.); 2) Transgressão (digitos executados além das opções 1, 2 e 3, incluindo letras, algarismos numéricos ou qualquer outro símbolo disponível no teclado do computador); 3) Desamparo / desistência (abaixo de 80 dígitações durante cada versão); 4) Tempo até desistir (em caso de não realização das 50 tentativas em ambas as versões, em qual tentativa houve a interrupção definitiva das digitações) e 5) Tempo até acerto (na versão CS, em qual tentativa o participante foi capaz de encontrar a senha 31 - acerto total - ou alguma outra que contivesse os dígitos 31 - acerto parcial - e, a partir daí, manter o mesmo padrão para interromper o ruído).

Nas variáveis cognitivas foi incluída, além das cinco variáveis já avaliadas no estudo piloto, a variável Declarou desistir de encontrar uma senha (ou seja, o participante declarou no questionário pós-teste que desistiu de tentar encontrar uma senha). Os dados foram analisados por dois avaliadores, que ao todo tiveram 16 discordâncias, representando um total de $95 \%$ de concordância para as 4 variáveis acima nas versões SS e CS. Como gênero (feminino e masculino) e sequência de testes (SS-CS e CS-SS) não apresentaram interferência nos resultados finais do estudo piloto, retiramos as análises dessas variáveis para o estudo principal. 
Para fazermos a comparação do padrão de digitação, entre as versões CS e SS (amostras dependentes) foi realizada por meio do teste de Wilcoxon, e entre os PJ e CN foi realizada a comparação do padrão de digitação por meio do teste U de Mann-Whitney, com análise post-hoc utilizando o teste de qui-quadrado para cada padrão de digitação.

\subsubsection{Considerações Éticas}

O estudo principal foi aprovado pela Comissão de Ética para Análise de Projetos de Pesquisa (CAPPesq) e inserido nos sistemas de controles internos do Hospital das Clinicas (SP3 e Sistema de Gestão) com o registro online $\mathrm{n}^{\mathrm{o}}$ 14526. Foi posteriormente inserido e aprovado na Plataforma Brasil com o n ${ }^{\circ}$ do parecer 1.437.926 em 04 de Março de 2016.

\subsubsection{Análise Estatística}

Para análise estatística, foi utilizada a mesma metodologia do estudo piloto. $\mathrm{O}$ tamanho da amostra desse estudo foi calculado com base nos achados do nosso estudo anterior, no qual foi encontrado que no teste com solução PJ recorreram a uma estratégia combinatória em 30\% dos casos, enquanto $\mathrm{CN}$ em $65 \%$ dos casos. Considerando-se alfa $=0,05$ e poder estatístico $=0,80$ em um teste binomial bicaudado para variável dicotômica temos, de acordo com Rosner (2000), a seguinte equação:

$N=(p 0)(q 0) \times[Z 1-\beta+Z 1-\alpha / 2) \times \sqrt{ }(p 1)(q 1) /(p 0)(q 0)] 2(p 1-p 0) 2$

$\mathrm{Na}$ equação acima, $\mathrm{p} 0$ corresponde à proporção de indivíduos que apresentam a estratégia correta no grupo $\mathrm{CN}$, q0 a proporção de indivíduos que apresentam a estratégia incorreta e p1 e q1 as proporções correspondentes no grupo de $\mathrm{PJ} . \mathrm{N}=(0,65)(0,35) \mathrm{x}$ $[1.96+0,84 \sqrt{ }(0,3)(0,7) /(0,65)(0,35)] 2=14,2 \approx 15$ indivíduos em $(0,3-0,65) 2$ cada grupo. Ou seja, uma amostra mínima de 30 sujeitos, que posteriormente ampliamos para 34 sujeitos em cada grupo. 
5. RESULTADOS 


\section{RESULTADOS}

\subsection{Estudo piloto}

O fluxograma abaixo mostra de forma ilustrativa as etapas de seleção da amostra:

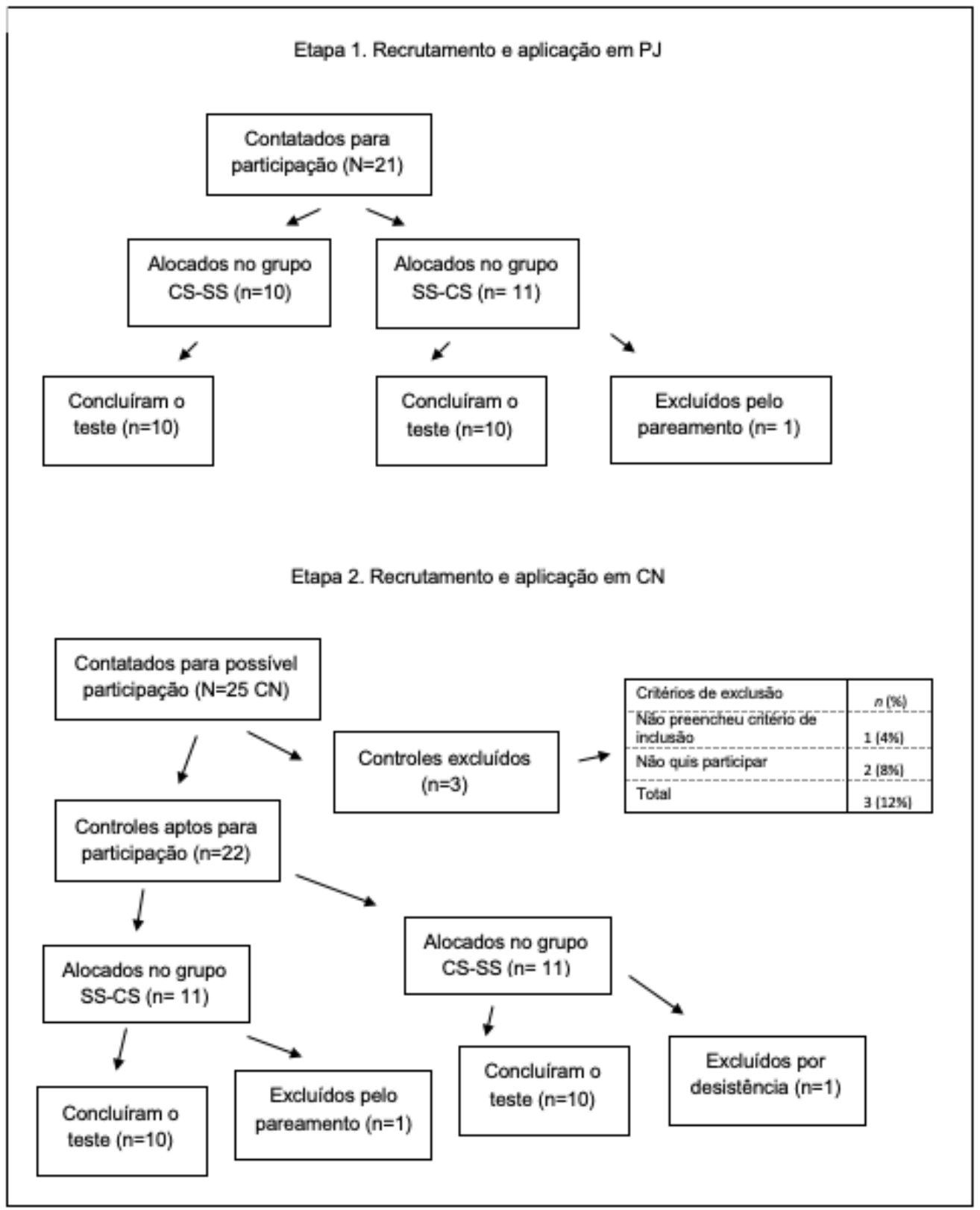

Figura 1 - Fluxograma de triagem e aplicação em PJ e CN - estudo piloto 
A amostra de PJ foi composta por $60 \%$ do sexo masculino, com idades variando de 27 a 70 anos ( $\operatorname{com} \mu=15,0 ; \mathrm{DP}=2,9)$. Não foram encontradas diferenças significativas em relação aos perfis demográficos entre $\mathrm{PJ}$ e $\mathrm{CN}$, exceto pela situação profissional, a qual alcançou significância com quase metade dos $\mathrm{PJ}$ desempregados $(\mathrm{p}=0,038)$. Além disso, o item de anos de educação formal se aproximou de uma diferença significativa $(\mathrm{p}=0,065)$. A Tabela 1 resume os principais achados.

Tabela 1 - Perfil sócio-demográfico de portadores de Transtorno do Jogo (PJ) e controles normais $(\mathrm{CN})$ selecionados para participar do estudo piloto $(\mathrm{N}=\mathbf{4 0})$

\begin{tabular}{|c|c|c|c|c|}
\hline & $\mathbf{P J}(\mathbf{n}=\mathbf{2 0})$ & $\mathrm{CN}(\mathrm{n}=\mathbf{2 0})$ & $\begin{array}{l}\text { Coef. [graus de } \\
\text { liberdade] }\end{array}$ & $\mathbf{p}$ \\
\hline \multicolumn{5}{|l|}{ Gênero } \\
\hline Masculino $-\mathrm{n}^{\mathrm{o}}(\%)$ & $12(60 \%)$ & $12(60 \%)$ & $\chi^{2}[1]=0^{b}$ & 1,000 \\
\hline Feminino $-\mathrm{n}^{\mathrm{o}}(\%)$ & $8(40 \%)$ & $8(40 \%)$ & & \\
\hline \multicolumn{5}{|l|}{ Idade } \\
\hline$\mu(\mathrm{DP})$ & $44,8(12,6)$ & $44,5[13,1]$ & $\mathrm{t}_{[48]}=-0,086$ & 0,932 \\
\hline \multicolumn{5}{|l|}{ Etnia } \\
\hline Caucasiano $-\mathrm{n}^{\mathrm{o}}(\%)$ & $16(80 \%)$ & $15(75 \%)$ & $\chi^{2}[1]=0,143$ & 0,705 \\
\hline Não-Caucasiano $-\mathrm{n}^{\circ}(\%)$ & $4(20 \%)$ & $5(25 \%)$ & & \\
\hline \multicolumn{5}{|l|}{ Estado civil } \\
\hline $\mathrm{C} / \mathrm{companheiro}-\mathrm{n}^{\circ}(\%)$ & $10(50 \%)$ & $9(45 \%)$ & $\chi_{[1]}^{2}=0,100$ & 0,752 \\
\hline $\mathrm{S} /$ companheiro $-\mathrm{n}^{\circ}(\%)$ & $10(50 \%)$ & $11(55 \%)$ & & \\
\hline \multicolumn{5}{|l|}{ Número de filhos } \\
\hline Sem filhos $-\mathrm{n}^{\circ}(\%)$ & $5(25 \%)$ & $8(40 \%)$ & $\chi_{[2]}^{2}=2,901$ & 0,234 \\
\hline 1 filho $-n^{o}(\%)$ & $9(45 \%)$ & $4(20 \%)$ & & \\
\hline$>1$ filho(s) $-\mathrm{n}^{\circ}(\%)$ & $6(30 \%)$ & $8(40 \%)$ & & \\
\hline \multicolumn{5}{|l|}{ Situação profissional } \\
\hline Com trabalho $-\mathrm{n}^{\circ}(\%)$ & $11(55 \%)$ & $17(85 \%)$ & $\chi^{2}[1]=4,286$ & $\underline{0,038}$ \\
\hline Sem trabalho $-\mathrm{n}^{\circ}(\%)$ & $9(45 \%)$ & $3(15 \%)$ & & \\
\hline \multicolumn{5}{|l|}{ Status socioeconômico ${ }^{a}$} \\
\hline$\mu(\mathrm{DP})$ & $5,93(3,15)$ & $6,42(3,63)$ & $\mathrm{t}_{[48]}=0,452$ & 0,654 \\
\hline $\begin{array}{c}\text { Anos de educação formal } \\
\mu \text { (DP) }\end{array}$ & $11,5(4,5)$ & $14,5(5,4)$ & $\mathrm{t}_{[48]}=1,897$ & 0,065 \\
\hline \multicolumn{5}{|l|}{ Local de Nascimento } \\
\hline SP Capital $-\mathrm{n}^{\circ}(\%)$ & $12(60 \%)$ & $13(65 \%)$ & $\chi^{2}[1]=0,107$ & 0,744 \\
\hline Outros $-\mathrm{n}^{0}(\%)$ & $8(40 \%)$ & $7(35 \%)$ & & \\
\hline \multicolumn{5}{|l|}{ Religião } \\
\hline Católica $-\mathrm{n}^{\circ}(\%)$ & $13(65 \%)$ & $12(60 \%)$ & $\chi^{2}[1]=0,107$ & 0,744 \\
\hline Outras $-\mathrm{n}^{\circ}(\%)$ & $7(35 \%)$ & $8(40 \%)$ & & \\
\hline
\end{tabular}

${ }^{a}$ Calculado por meio da soma do número total de cômodos, banheiros, automóveis de passeio, televisões coloridas, empregados, aparelhos de som, máquinas de lavar, leitor de DVD ou símile, computadores, geladeiras e aspiradores de pó ou equivalente, existentes na moradia do indivíduo, dividido pelo total de habitantes (IBGE, 1998).

${ }^{\mathrm{b}}$ Correção de Yates para tabelas 2x2. 
Comparando as duas versões do TCARC (CS e SS), os participantes relataram maior ansiedade, menos felicidade e menos confiança enquanto realizavam a versão SS. Além disso, apresentaram maior número de acertos e maior frequência de digitação aleatória na versão SS. Embora tenha havido maior frequência de comportamentos supersticiosos durante o TCARC da versão SS em comparação com a condição CS, essa diferença não foi significativa. Quanto aos aspectos cognitivos, 15 (47,5\%) entrevistados declararam ter utilizado uma estratégia durante a versão SS do teste, enquanto $25(62,5 \%)$ declararam ter utilizado uma estratégia durante a versão CS. No entanto, essa diferença também não foi estatisticamente significante $(p=0,109)$.

Os entrevistados relataram menos controle sobre o ruído durante a versão incontrolável, e acreditavam menos na existência de um código para interromper o ruído para o TCARC incontrolável, e seu grau de confiança na resposta para a versão incontrolável era menor do que sua confiança em relação às versões controláveis. Ao confrorntarmos as duas condições, 24 (60\%) participantes identificaram corretamente as duas versões, $11(27,5 \%)$ acreditavam que havia um código de combinação correto para ambas as versões, $4(10,0 \%)$ acreditavam que não havia combinação correta para ambas as versões e 1 indivíduo (2,5\%) identificou erroneamente as duas versões. A proporção que identificou corretamente as versões de teste incontrolável e controlável não foi estatisticamente diferente entre os dois testes, mas os entrevistados tiveram menos certeza de suas conclusões sobre o teste incontrolável do que sobre a versão controlável.

A Tabela 2 resume os principais resultados da comparação de desempenho nas duas versões do TCARC. 
Tabela 2 - Comparação de desempenho nos testes curtos de análise respostaconsequência (TCARC) entre as versões sem solução (SS) e com solução (CS) ( $\mathrm{N}=40)$

\begin{tabular}{|c|c|c|c|c|}
\hline Tipo de Resposta & SS & CS & Coef. & $\mathbf{p}$ \\
\hline \multicolumn{5}{|l|}{ Afetiva: } \\
\hline Ansiedade - M (amplitude) & $3,5(0-10,0)$ & $0(0-10,0)$ & $Z=2,869$ & $\underline{0,004}$ \\
\hline Felicidade - M (amplitude) & $3,5(0-7,0)$ & $3,5(0-10,0)$ & $Z=-3,188$ & $\underline{0,001}$ \\
\hline Confiança - M (amplitude) & $3,5(0-7,0)$ & $5,2(0-10,0)$ & $Z=-2,045$ & $\underline{0,041}$ \\
\hline \multicolumn{5}{|l|}{ Comportamental: } \\
\hline $\begin{array}{l}\text { Total de número de dígitados - } \\
\mu \text { (DP) }\end{array}$ & $83,6(50,6)$ & $46,3(25,7)$ & $\mathfrak{t}=-5,214$ & $\leq 0,001$ \\
\hline Digitação aleatória - no (\%) & $22(55 \%)$ & $8(20 \%)$ & $*$ & 0.003 \\
\hline $\begin{array}{l}\text { Comportamento supersticioso } \\
-n^{\circ}(\%)\end{array}$ & $8(40 \%)$ & $3(15 \%)$ & $*$ & 0,227 \\
\hline \multicolumn{5}{|l|}{ Cognitiva: } \\
\hline $\begin{array}{l}\text { Declarou usar estratégia }-\mathrm{n}^{\circ} \\
(\%)\end{array}$ & $15(47,5 \%)$ & $25(62,5 \%)$ & $*$ & 0,109 \\
\hline $\begin{array}{l}\text { Percepção de controle - M } \\
\text { (amplitude) }\end{array}$ & $0(0-10,0)$ & $6,5(0-10,0)$ & $Z=-5,064$ & $\leq 0,001$ \\
\hline $\begin{array}{l}\text { Acreditou que o teste era } \\
\text { controlável }-\mathrm{n}^{\circ}(\%)\end{array}$ & $12(30 \%)$ & $35(87,5 \%)$ & $*$ & $\leq 0,001$ \\
\hline $\begin{array}{l}\text { Convicção sobre a existência } \\
\text { de uma senha - M (amplitude) }\end{array}$ & $7,0(0-10,0)$ & $10(0-10,0)$ & $Z=-2,864$ & $\underline{0,004}$ \\
\hline
\end{tabular}

*Teste de McNemar

Em análise adicional, para as duas versões de teste (CS e SS) verificamos que a taxa de concordância entre o registro do computador e o relatório verbal sobre o uso de uma estratégia combinatória foi idêntica em $62,5 \%(n=25)$. No entanto, o tipo de discordância foi diferente de acordo com a versão do teste. Dos 12 indivíduos que relataram ter usado uma estratégia que não foi objetivamente verificada nos registros do computador, $11(91,7 \%)$ apresentaram essa inconsistência enquanto realizavam a versão SS $(p=0,006)$. Por outro lado, dos 17 indivíduos que negaram usar uma estratégia combinatória que foi efetivamente identificada no registro do computador, $14(82,4 \%)$ apresentaram essa inconsistência enquanto realizavam a versão $C S(p=0,021)$. 


\subsubsection{Comparação do desempenho de PJ e CN no TCARC - versão CS}

Comparado aos participantes do grupo $\mathrm{CN}$, os PJ relataram maior ansiedade $(p=0,044)$ e níveis semelhantes de felicidade $(p=0,667)$ e confiança $(p=0,176)$. Eles experimentaram percepção semelhante de controle sobre os ruídos durante a tarefa. Em relação às respostas comportamentais, o PJ atingiu o painel de digitação mais vezes do que os $\mathrm{CN}$, mas essa diferença não foi significativa $(\mathrm{p}=0,110)$. PJ demonstrou maior digitação aleatória na tarefa $(p=0,018)$, e não foram encontradas diferenças quanto aos comportamentos supersticiosos entre os dois grupos.

Quanto aos aspectos cognitivos, o grupo PJ relatou usar menos estratégias $(\mathrm{p}=0,027)$. Um quarto dos PJ não acreditava que houvesse um código para controlar os ruídos, enquanto todos os $\mathrm{CN}$ acreditavam que havia um código correto $(\mathrm{p}=0,017)$. No entanto, não houve diferença quanto à identificação do código correto para $\mathrm{PJ}$ e os $\mathrm{CN}$ $(p=0,342)$ e ambos estavam igualmente confiantes em relação à resposta. Ao contrastar as respostas comportamentais e cognitivas, a taxa de concordância entre o registro do computador e os relatos verbais sobre a estratégia utilizada foi de 55\% para PJ $\left(\mathrm{n}^{\mathrm{0}}=11\right)$ e $70 \%$ para $\mathrm{CN}\left(\mathrm{n}^{\circ}=14\right)$, no entanto, essa diferença não foi estatisticamente diferente $(p=0,327)$. A tabela 3 resume os principais resultados encontrados. 
Tabela 3 - Comparação de desempenho no teste curto de análise respostaconsequência (TCARC) entre portadores de Transtorno do Jogo (PJ) e controles normais $(C N)$ na versão com solução $(C S)(N=40)$

\begin{tabular}{|c|c|c|c|c|}
\hline Tipo de Resposta & PJ $(n=20)$ & $\mathrm{CN}(\mathrm{n}=\mathbf{2 0})$ & Coef. & $\mathbf{p}$ \\
\hline \multicolumn{5}{|l|}{ Afetiva: } \\
\hline Ansiedade - M (amplitude) & $1,8(0-10,0)$ & $0(0-3,5)$ & $\mathrm{U}=262,0$ & $\underline{0,044}$ \\
\hline Felicidade - M (amplitude) & $3,5(0-7,0)$ & $3,5(0-7,0)$ & $\mathrm{U}=185,0$ & 0,667 \\
\hline Confiança - M (amplitude) & $3,5(0-10,0)$ & $6,9(0-10,0)$ & $\mathrm{U}=153,5$ & 0,176 \\
\hline \multicolumn{5}{|l|}{ Comportamental: } \\
\hline $\begin{array}{l}\text { Total de número de dígitados - } \\
\mu \text { (DP) }\end{array}$ & $52,8(28,5)$ & $39,8(21,5)$ & $\mathrm{t}=-1,637$ & 0,110 \\
\hline Digitação aleatória - nº $(\%)$ & $7(35 \%)$ & $1(5 \%)$ & $\chi^{2}=5,625$ & $\underline{0,018}$ \\
\hline $\begin{array}{l}\text { Comportamento supersticioso } \\
-\mathrm{n}^{\mathrm{o}}(\%)\end{array}$ & $1(5 \%)$ & $2(10 \%)$ & $\chi^{2}=0,360$ & 0,548 \\
\hline \multicolumn{5}{|l|}{ Cognitiva: } \\
\hline $\begin{array}{l}\text { Declarou usar uma estratégia - } \\
n^{\circ}(\%)\end{array}$ & $6(30 \%)$ & $13(65 \%)$ & $\chi^{2}=4,912$ & $\underline{0,027}$ \\
\hline $\begin{array}{l}\text { Percepção de controle }-\mu \\
\text { (DP) }\end{array}$ & $5,8(2,7)$ & $6,3(2,9)$ & $\mathrm{t}=0,552$ & 0,584 \\
\hline $\begin{array}{l}\text { Acreditou que o teste era } \\
\text { controlável }-\mathrm{n}^{\circ}(\%)\end{array}$ & $15(75 \%)$ & $20(100 \%)$ & $\chi^{2}=5,714$ & $\underline{0,017}$ \\
\hline $\begin{array}{l}\text { Convicção sobre a existência } \\
\text { de uma senha - M (amplitude) }\end{array}$ & $7,8(0-10,0)$ & $10,0(0-10,0)$ & $\mathrm{U}=445,0$ & 0,171 \\
\hline $\begin{array}{l}\text { Acertou a senha (código } 31)- \\
n^{\circ}(\%)\end{array}$ & $9(45 \%)$ & $12(60 \%)$ & $\chi^{2}=0,901$ & 0,342 \\
\hline
\end{tabular}

Três variáveis que atingiram o limiar para significância potencial na comparação entre os grupos $(p<0,10)$ foram inseridas em uma regressão logística, tendo o grupo diagnóstico como variável dependente: ansiedade, digitação aleatória e declarar usar estratégia. Anos de educação formal e status profissional foram adicionadas para controle das variações no perfil demográfico. A variável crença na existência de um código de controle não foi incluída porque todos os indivíduos do grupo $\mathrm{CN}$ declararam acreditar na existência desse código, elevando artificialmente as estimativas de proporção entre os grupo ao infinito. O modelo final foi significativo $\left(\chi^{2}[2]=11,44\right.$, $\mathrm{p}=0,003 ; \mathrm{R} 2$ de Nagelkerke=0,332) com uma classificação correta de 29 (72,5\%) indivíduos. Duas variáveis permaneceram no modelo final: "ansiedade ao fazer o teste" $(\mathrm{OR}=1,52$, intervalo de confiança de 95\%: 1,01-2,29, p=0,045) e "digitação aleatória" $(\mathrm{OR}=12,58$, intervalo de confiança de $95 \% 1,28-123,9, \mathrm{p}=0,030)$, ambos maiores para 
PJ quando comparados aos CN. Em um modelo alternativo, experimentamos incluir a variável "crença na existência de um código de controle". Para isso, localizamos o indivíduo entre os $\mathrm{CN}$ que era o menos convicto de sua resposta quanto ao código de controle e imputamos um valor "0" para essa variável, a fim de evitar uma célula com contagem nula no modelo de regressão. Em seguida, executamos um modelo logístico passo a passo com todas as variáveis previamente selecionadas mais a variável modificada "crença na existência de um código de controle", todavia ela foi excluída no processo passo-a-passo e o resultado final foi semelhante ao anterior.

\subsubsection{Comparação do desempenho do PJ e CN no TCARC - versão SS}

Tanto o PJ quanto os CN ficaram igualmente descontentes ao tomar o TCARC incontrolável. Comparado aos CN, o PJ apresentou uma tendência a ter menos confiança durante a tarefa $(p=0,096)$. Não foram encontradas diferenças em relação ao número de respostas digitadas. A taxa de digitação aleatória se aproximou da significância, com uma proporção maior de PJ adotando essa estratégia em comparação aos CN (70\% vs. 40\%, $\mathrm{p}=0,057)$. Não foram encontradas diferenças quanto aos comportamentos supersticiosos entre os dois grupos.

Quanto aos aspectos cognitivos, semelhantes aos resultados da versão controlável, o PJ apresentou menor probabilidade de relatar usando qualquer estratégia do que os $\mathrm{CN}(40 \%$ vs. $85 \%, \mathrm{p}=0,003)$. Não foram encontradas diferenças em relação à percepção de controle ( $\mathrm{p}=0,738$ ), com a maioria dos indivíduos expressando não sentir nenhum controle sobre o ruído irritante $(67,5 \%)$. Surpreendentemente, os CN relataram com maior frequência do que PJ que eles acreditavam que poderia haver um código de controle para os ruídos $(45 \%$ vs. $15 \%, \mathrm{p}=0,038)$. Eles também relataram maior confiança do que o PJ em relação às respostas, porém essa diferença não foi estatisticamente significante $(\mathrm{p}=0,231)$. Quanto à concordância entre a resposta comportamental capturada pelos registros do computador e o relato verbal, os participantes do grupo $\mathrm{CN}$ apresentaram maior frequência de discordância que o PJ (50\% vs. 25\%), porém essa diferença não foi estatisticamente significante $(p=0,102)$. A tabela 4 resume os principais achados. 
Tabela 4 - Comparação de desempenho no teste curto de análise respostaconsequência (TCARC) entre portadores de Transtorno do Jogo $(P J)$ e controles normais $(\mathrm{CN})$ na versão sem solução $(\mathrm{SS})(\mathrm{N}=40)$

\begin{tabular}{|c|c|c|c|c|}
\hline Tipo de Resposta & PJ $(n=20)$ & $\mathrm{CN}(\mathrm{n}=\mathbf{2 0})$ & Coef. & $\mathbf{p}$ \\
\hline \multicolumn{5}{|l|}{ Afetiva: } \\
\hline Ansiedade - M (amplitude) & $3,5(0-10,0)$ & $3,5(0-10,0)$ & $\mathrm{U}=218,0$ & 0,640 \\
\hline Felicidade - M (amplitude) & $0(0-7,0)$ & $1,8(0-7,0)$ & $\mathrm{U}=146,0$ & 0,149 \\
\hline Confiança - M (amplitude) & $3,5(0-7,0)$ & $3,5(0-7,0)$ & $\mathrm{U}=138,0$ & 0,096 \\
\hline \multicolumn{5}{|l|}{ Comportamental: } \\
\hline $\begin{array}{l}\text { Total de número de dígitados }-\mu \\
\text { (DP) }\end{array}$ & $79,6(44,5)$ & $87,7(56,9)$ & $\mathrm{t}=0,504$ & 0,617 \\
\hline Digitação aleatória - $\mathrm{n}^{\mathrm{o}}(\%)$ & $14(70 \%)$ & $8(40 \%)$ & $\chi^{2}=3,636$ & 0,057 \\
\hline $\begin{array}{l}\text { Comportamento supersticioso - } \\
\mathrm{n}^{\circ}(\%)\end{array}$ & $3(15 \%)$ & $5(25 \%)$ & $\chi^{2}=0,625$ & 0,429 \\
\hline \multicolumn{5}{|l|}{ Cognitiva: } \\
\hline $\begin{array}{l}\text { Declarou usar uma estratégia }-\mathrm{n}^{\mathrm{o}} \\
(\%)\end{array}$ & $8(40 \%)$ & $17(85 \%)$ & $\chi^{2}=8,640$ & $\underline{0,003}$ \\
\hline $\begin{array}{l}\text { Percepção de controle - M } \\
\text { (amplitude) }\end{array}$ & $0(0-10,0)$ & $0(0-6,0)$ & $\mathrm{U}=213,0$ & 0,738 \\
\hline $\begin{array}{l}\text { Acreditou que o teste era } \\
\text { controlável }-\mathrm{n}^{\circ}(\%)\end{array}$ & $3(15 \%)$ & $9(45 \%)$ & $\chi^{2}=4,286$ & $\underline{0,038}$ \\
\hline $\begin{array}{l}\text { Convicção sobre a existência de } \\
\text { uma senha - M (amplitude) }\end{array}$ & $3,5(0-10,0)$ & $6,9(0-10,0)$ & $U=155,0$ & 0,231 \\
\hline
\end{tabular}

Três variáveis que atingiram o limiar para significância potencial na comparação entre os grupos $(\mathrm{p}<0,10)$ foram inseridas em uma regressão logística, tendo o grupo diagnóstico como variável dependente: confiança, digitação aleatória e crença na existência de uma senha. Anos de educação formal e status profissional foram adicionadas para controle das variações no perfil demográfico. A variável declarou usar uma estratégia covaria com digitação aleatória $\left(\chi^{2}[1]=3,52 ; \mathrm{p}=0,060\right)$, portanto, foi tomada a decisão de abandonar a primeira, porque a digitação aleatória poderia ser objetivamente verificada. O modelo final foi significativo $\left(\chi^{2}{ }_{[2]}=9,06, p=0,011 ; R^{2}\right.$ de Nagelkerke $=0,270$ ) com uma taxa de classificação correta semelhante ao modelo anterior $(\mathrm{n}=29 ; 72,5 \%)$. Duas variáveis permaneceram no modelo final: mais $\mathrm{CN}$ afirmaram acredita que existe uma senha $(\mathrm{OR}=0,164$, intervalo de confiança de 95\%: 0,031-0,852; $\mathrm{p}=0,032)$, mas mais $\mathrm{PJ}$ apresentaram digitação aleatória $(\mathrm{OR}=4,579$, intervalo de confiança de 95\% 1,07-19,6; $\mathrm{p}=0,040)$. 
Uma regressão alternativa foi conduzida com a variável declarou usar estratégia substituindo digitação aleatória como fator, sendo que somente esta sobreviveu no modelo final anulando a variável acredita que havia uma senha. Esse modelo alternativo foi significativo $\left(\chi_{[1]}^{2}=9,10 ; p=0,03 ; R^{2}\right.$ de Nagelkerke=0,271) ainda com mais $C N$ declarando usar alguma estratégia durante o teste $(\mathrm{OR}=0,118$; intervalo de confiança de $95 \%$ 0,026-0,557; $\mathrm{p}=0,06)$, isto é recorrendo menos à digitação aleatória do que os PJ.

Finalmente, ao examinar as crenças dos participantes em relação à existência de um código nos dois testes, os participantes do grupo $\mathrm{CN}$ foram mais propensos a acreditar falsamente que existia um código correto para ambos os testes que o PJ (45\% vs. 10\%; $\left.\chi^{2}=6,144 ; \mathrm{p}=0,013\right)$.

Em relação a gênero e sequência dos testes, não foram encontradas diferenças em relação ao desempenho de homens e mulheres, exceto pelo número de dígitos na versão $\mathrm{SS}$, com homens digitando mais números $(\operatorname{com} \mu=100,2 ; \mathrm{DP}=54,7)$ em comparação às mulheres ( $\operatorname{com} \mu=58,8 ; \mathrm{DP}=31,3 ; \mathrm{t}=-3,03 ; \mathrm{p}=0,004)$. Todos os participantes que começaram com a versão CS declararam ter mantido a mesma estratégia ao passar de uma versão para a seguinte, enquanto apenas 11 indivíduos (55\%) que começaram com a versão SS mantiveram a mesma estratégia para ambas as versões, o que foi estatisticamente significante $\left(\chi^{2}=11,61 ; p=0,001\right)$. 


\subsection{Estudo principal}

O fluxograma abaixo mostra de forma ilustrativa as etapas dessa seleção das amostra:

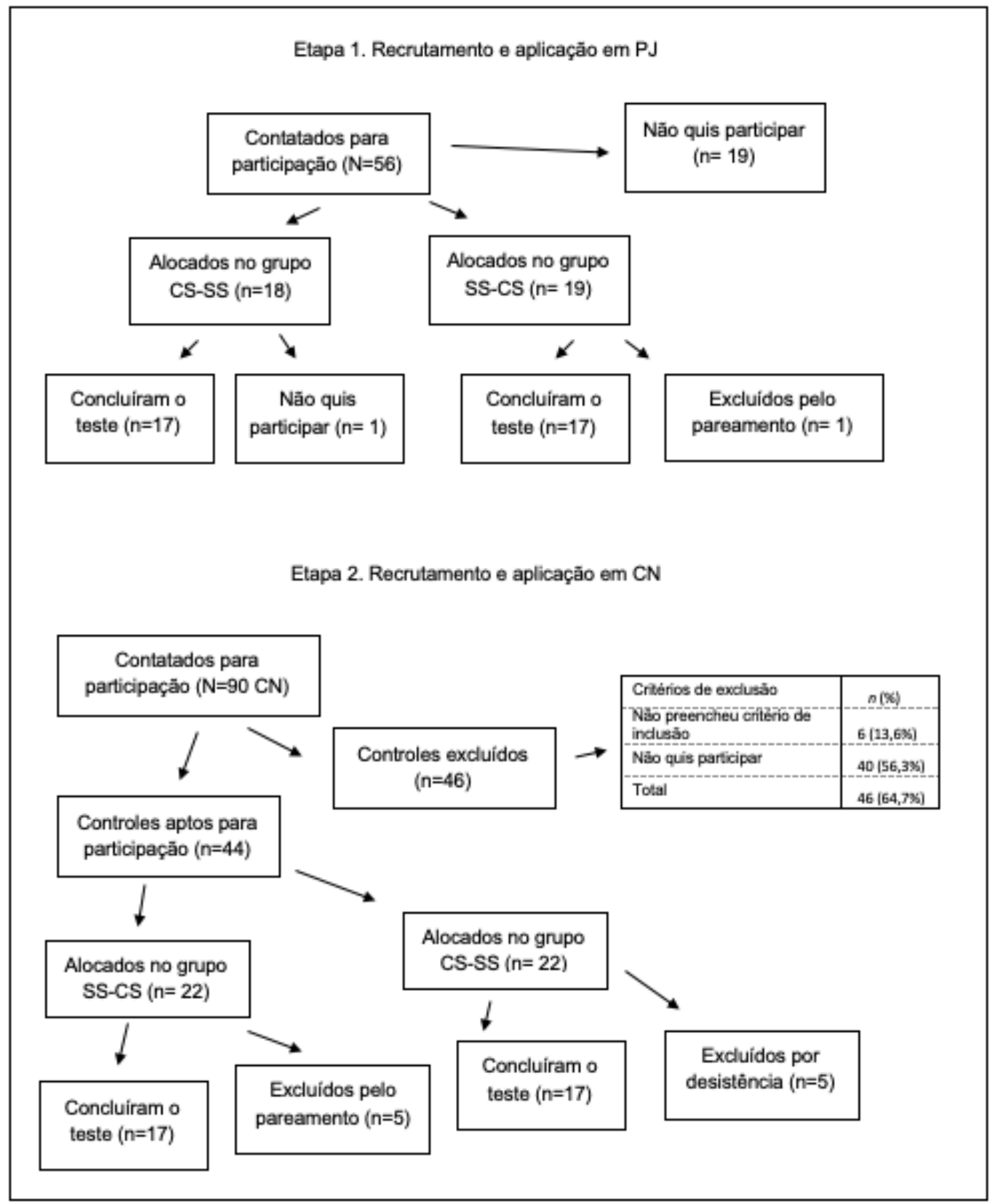

Figura 2 - Fluxograma de triagem e aplicação PJ e CN - estudo principal

Ao final, 68 indivíduos participaram do estudo, 34 PJ e $34 \mathrm{CN}$, sendo que todos leram e concordaram em assinar o TCLE. De modo geral, verificamos que a maioria dos PJ eram homens (65\%), com uma média geral de 45 anos, 48 (71\%) caucasianos, 13 anos de educação formal, perfil sócio-econômico compatível com classe B ou A, 36 (53\%) 
sem companheiro(a), 44 (65\%) com filhos, 46 (68\%) com trabalho, $36(53 \%)$ oriundos de SP Capital, e 51 (75\%) católicos. O perfil demográfico de PJ e CN foi consideravelmente similar, exceto por estado civil e status sócio-econômico, com os PJ apresentando maior frequência de indivíduos solteiros e menor status sócio-econômico ( com $\mathrm{p}=0,015$ e $\mathrm{p}=0,015$, respectivamente). Esses dois fatores foram posteriormente analisados como covariáveis na regressão logística binária. A tabela abaixo resume os principais achados.

Tabela 5 - Perfil sócio-demográfico de portadores de Transtorno do Jogo (PJ) e controles normais $(\mathrm{CN})$ selecionados para participar do estudo principal $(\mathbf{N}=68)$

\begin{tabular}{|c|c|c|c|c|}
\hline & $\mathbf{P J}(n=34)$ & $\mathrm{CN}(\mathrm{n}=34)$ & $\begin{array}{l}\text { Coef. [graus } \\
\text { de liberdade] }\end{array}$ & $\mathbf{p}$ \\
\hline \multicolumn{5}{|l|}{ Gênero } \\
\hline Masculino - $\mathrm{n}^{\circ}(\%)$ & $22(65 \%)$ & $22(65 \%)$ & \multirow[t]{2}{*}{$\chi^{2}[1]=0^{b}$} & \multirow[t]{2}{*}{1} \\
\hline Feminino $-\mathrm{n}^{\mathrm{o}}(\%)$ & $12(35 \%)$ & $12(35 \%)$ & & \\
\hline \multicolumn{5}{|l|}{ Idade } \\
\hline$\mu(\mathrm{DP})$ & $45,3(12,32)$ & $45,7(12,53)$ & $\mathrm{t}_{[66]}=0,117$ & 0,91 \\
\hline \multicolumn{5}{|l|}{ Etnia } \\
\hline Caucasiano $-\mathrm{n}^{\mathrm{o}}(\%)$ & $23(68 \%)$ & $25(74 \%)$ & \multirow[t]{2}{*}{$\chi^{2}[1]=0,283$} & \multirow[t]{2}{*}{0,595} \\
\hline Não caucasiano $-\mathrm{n}^{\circ}(\%)$ & $11(32 \%)$ & $9(26 \%)$ & & \\
\hline \multicolumn{5}{|l|}{ Estado civil } \\
\hline $\mathrm{C} /$ companheiro $-\mathrm{n}^{\circ}(\%)$ & $11(32 \%)$ & $21(62 \%)$ & \multirow[t]{2}{*}{$\chi_{[1]}^{2}=5,903$} & \multirow[t]{2}{*}{$\underline{0,015}$} \\
\hline $\mathrm{S} /$ companheiro $-\mathrm{n}^{\mathrm{o}}(\%)$ & $23(68 \%)$ & $13(38 \%)$ & & \\
\hline \multicolumn{5}{|l|}{ Filhos } \\
\hline Sem filhos $-\mathrm{n}^{\circ}(\%)$ & $9(26 \%)$ & $15(44 \%)$ & \multirow[t]{2}{*}{$\chi^{2}[1]=2,318$} & \multirow[t]{2}{*}{0,13} \\
\hline 1 ou $>$ filhos $-\mathrm{n}^{\mathrm{o}}(\%)$ & $25(74 \%)$ & $19(56 \%)$ & & \\
\hline \multicolumn{5}{|l|}{ Situação profissional } \\
\hline Com trabalho $-\mathrm{n}^{\circ}(\%)$ & $21(62 \%)$ & $25(74 \%)$ & \multirow{2}{*}{$\chi_{[1]}^{2}=1,075$} & \multirow[t]{2}{*}{0,31} \\
\hline Sem trabalho $-\mathrm{n}^{\mathrm{o}}(\%)$ & $13(38 \%)$ & $9(26 \%)$ & & \\
\hline \multicolumn{5}{|l|}{ Status socioeconômico ${ }^{a}$} \\
\hline$\mu(\mathrm{DP})$ & $5,4(2,7)$ & $7,0(3,4)$ & $\mathrm{t}_{[66]}=2,502$ & $\underline{0,015}$ \\
\hline \multicolumn{5}{|l|}{ Anos de educação formal } \\
\hline \multicolumn{5}{|l|}{ Local de Nascimento } \\
\hline São Paulo Capital - nº (\%) & $17(50 \%)$ & $19(56 \%)$ & \multirow[t]{2}{*}{$\chi_{[1]}^{2}=0,236$} & \multirow[t]{2}{*}{0,627} \\
\hline Outros $-\mathrm{n}^{\mathrm{o}}(\%)$ & $17(50 \%)$ & $15(44 \%)$ & & \\
\hline \multicolumn{5}{|l|}{ Religião } \\
\hline Católica - n ${ }^{\circ}(\%)$ & $28(82 \%)$ & $23(68 \%)$ & \multirow[t]{2}{*}{$\chi_{[1]}^{2}=1,961$} & \multirow[t]{2}{*}{0,166} \\
\hline Outras $-\mathrm{n}^{\circ}(\%)$ & $6(18 \%)$ & $11(32 \%)$ & & \\
\hline
\end{tabular}


Comparando as duas versões do TLARC (CS e SS), os participantes relataram maior ansiedade no teste SS, enquanto que a felicidade e a confiança foram relatadas como mais altas no teste CS. Nas variáveis comportamentais, o total de números digitados foi maior na versão SS como esperado. Quanto ao padrão de digitação, encontramos uma tendência à significância $(\mathrm{p}=0,097)$. Os comportamentos supersticiosos ocorreram mais na versão SS, a transgressão foi mais frequente na versão SS e as desistências ocorreram com mais frequência na versão SS, bem como o tempo até desistir foi menor na versão SS. Com relação às variáveis cognitivas, não verificamos diferença entre as versões quanto ao relato de uso de estratégia. Já a percepção de controle, a crença de que o teste era controlável e o grau de convicção sobre a resposta foram mais frequentes na versão CS. A tabela 6 mostra um resumo dos principais resultados. 
Tabela 6 - Comparação de desempenho nos testes longos de análise respostaconsequência (TLARC) entre as versões sem solução (SS) e com solução $(\mathrm{CS})(\mathrm{N}=68)$

\begin{tabular}{|c|c|c|c|c|}
\hline Tipo de Resposta & SS & CS & Coef. & $\mathbf{p}$ \\
\hline \multicolumn{5}{|l|}{ Afetiva: } \\
\hline Ansiedade - M (amplitude) & $2,9(0-10,0)$ & $2,3(0-10,0)$ & $Z=-2,098$ & $\underline{0,036}$ \\
\hline Felicidade - M (amplitude) & $1,5(0-7,0)$ & $2,8(0-10,0)$ & $Z=-3,169$ & $\underline{0,002}$ \\
\hline Confiança - M (amplitude) & $3,7(0-10,0)$ & $4,8(0-10,0)$ & $Z=-3,331$ & $\underline{0,001}$ \\
\hline \multicolumn{5}{|l|}{ Comportamental: } \\
\hline $\begin{array}{l}\text { Total de número de dígitados - } \\
\mu \text { (DP) }\end{array}$ & $371,1(327,4)$ & $254,3(247,3)$ & $\mathrm{t}=2,482$ & $\underline{0,016}$ \\
\hline \multicolumn{5}{|l|}{ Padrão de digitação - no $(\%)$} \\
\hline $\begin{array}{l}\text { - Ausente (digitação } \\
\text { aleatória) }\end{array}$ & $44(64,7 \%)$ & $56(82,4 \%)$ & $Z=1,661$ & 0,097 \\
\hline $\begin{array}{l}\text { - Parcial I (aleatório > } \\
\text { combinatório) }\end{array}$ & $7(10,3 \%)$ & $3(4,4 \%)$ & & \\
\hline $\begin{array}{l}\text { - Parcial II (combinatório > } \\
\text { aleatório) }\end{array}$ & $5(7,4 \%)$ & $2(2,9 \%)$ & & \\
\hline $\begin{array}{l}\text { - Completo (digitação } \\
\text { combinatória) }\end{array}$ & $12(17,6 \%)$ & $7(10,3 \%)$ & & \\
\hline $\begin{array}{l}\text { Comportamento supersticioso } \\
-n^{\circ}(\%)\end{array}$ & $31(46 \%)$ & $23(34 \%)$ & $*$ & 0,230 \\
\hline Transgressão $-\mathrm{n}^{\mathrm{o}}(\%)$ & $24(35 \%)$ & $5(7 \%)$ & $*$ & $\leq 0,001$ \\
\hline Desamparo / desistiu - $\mathrm{n}^{\mathrm{o}}(\%)$ & $22(32 \%)$ & $9(13 \%)$ & $*$ & $\underline{0,011}$ \\
\hline $\begin{array}{l}\text { Número de tentativas até } \\
\text { desistir }-\mu(\mathrm{DP})\end{array}$ & $37,4(2,1)$ & $43,8(1,6)$ & $\mathrm{t}=-2,450$ & $\underline{0,017}$ \\
\hline \multicolumn{5}{|l|}{ Cognitiva: } \\
\hline Declarou usar estratégia (\%) & $43(63,2 \%)$ & $43(63,2 \%)$ & $*$ & 1 \\
\hline $\begin{array}{l}\text { Desistiu de encontrar uma } \\
\text { senha }-n^{\circ}(\%)\end{array}$ & $26(38 \%)$ & $17(25 \%)$ & $*$ & 0,108 \\
\hline $\begin{array}{l}\text { Percepção de controle }-\mathrm{M} \\
\text { (amplitude) }\end{array}$ & $0,7(0-7,0)$ & $4,6(0-10,0)$ & $Z=-5,872$ & $\leq 0,001$ \\
\hline $\begin{array}{l}\text { Acreditou que o teste era } \\
\text { controlável }-\mathrm{n}^{\circ}(\%)\end{array}$ & $9(13,2 \%)$ & $48(70,6 \%)$ & $*$ & $\leq 0,001$ \\
\hline $\begin{array}{l}\text { Convicção sobre a existência } \\
\text { de uma senha - M (amplitude) }\end{array}$ & $6,1(0-10,0)$ & $7,6(0-10,0)$ & $Z=-3,525$ & $\leq 0,001$ \\
\hline
\end{tabular}

$\mathrm{Na}$ análise post-hoc binária para padrões de digitação, usando o teste de McNemar, encontramos que o padrão de digitação aleatória foi mais frequente no teste CS do que no SS $(p=0,036)$; os padrões predominantemente aleatório $(p=0,219)$, 
predominantemente combinatório $(\mathrm{p}=0375)$ e combinatório completo $(\mathrm{p}=0,359)$ não apresentaram frequência significativamente diferente entre as versões SS e CS. No TLARC versão CS o "número de tentativas até descobrir a senha" foi de $\mu=10,2$ $(\mathrm{DP}=12,8)$. Também verificamos que $26(38,2 \%)$ pessoas acertaram a senha, $33(48,5 \%)$ pessoas erraram a senha e $9(13,2 \%)$ tiveram acerto parcial, com $\chi^{2}=13,441$ e $p=0,001$. Além disso, $31(45,6 \%)$ participantes declararam ter utilizado a mesma estratégia em ambos os teste e $42(61,8 \%)$ pessoas avaliaram corretamente os testes, isto é, identificou qual era o teste que tinha solução e qual teste não tinha solução.

Em análise adicional, para as duas versões de teste (CS e SS) sobre a taxa de concordância entre o registro do computador e o relatório verbal sobre o uso de uma estratégia combinatória, verificamos que, na versão SS, $29(42,6 \%)$ pessoas foram consistentes em suas respostas, e $39(57,4 \%)$ não foram consistentes entre a resposta comportamental e a resposta relatada. Já na versão CS, $31(45,6 \%)$ pessoas foram consistentes em suas respostas, e $37(54,4 \%)$ não foram consistentes entre a resposta comportamental e a resposta relatada. O erro mais comum entre os participantes foi o de relatar uso de estratégia quando nenhuma estratégia foi identificada. A tabela 7 resume os principais achados.

Tabela 7 - Análise de concordância entre 0 autorrelato e $\quad$ o registro computadorizado para o uso de estratégia $(\mathrm{N}=68)$

\begin{tabular}{ccccc}
\hline VERSÃO CS & \multicolumn{2}{c}{ Registro Computadorizado } & & \\
\hline Autorrelato & $\begin{array}{c}\text { Sem estratégia } \\
\text { identificada }\end{array}$ & $\begin{array}{c}\text { Estratégia combinatória } \\
\text { identificada }\end{array}$ & Kappa & p \\
\hline $\begin{array}{c}\text { Negou uso de } \\
\text { estratégia } \\
\text { Refere uso de } \\
\text { estratégia }\end{array}$ & $\begin{array}{c}22(32 \%) \\
(50 \%)-\text { Erro } \\
1\end{array}$ & $3(4 \%)-$ Erro 2 & 0,071 & 0,352 \\
\hline $\begin{array}{c}\text { VERSÃO SS } \\
\text { Autorrelato }\end{array}$ & $\begin{array}{c}\text { Sem estratégia } \\
\text { identificada }\end{array}$ & $\begin{array}{c}\text { Estratégia combinatória } \\
\text { identificada }\end{array}$ & Kappa & p \\
\hline $\begin{array}{c}\text { Negou uso de } \\
\text { estratégia } \\
\text { Refere uso de } \\
\text { estratégia }\end{array}$ & $\begin{array}{c}15(22 \%) \\
(42,6 \%)-\text { Erro } \\
1\end{array}$ & $10(14.7 \%)-$ Erro 2 & & \\
\hline
\end{tabular}


$\mathrm{Na}$ análise post-hoc binária com teste de McNemar sobre as inconsistências de relato sobre uso de estratégia, encontramos que o Erro 1 (afirmar ter usado estratégia combinatória, sendo que isso não foi identificado no registro do computador) foi mais frequente na versão SS do que na $\mathrm{CS}$, respectivamente 14,7 vs. $4,4 \%(\mathrm{p}=0,065)$, enquanto o Erro 2 (negar o uso de estratégia combinatória, quando o registro do computador sugere o contrário) foi aproximadamente $42,6 \%$ vs. $50 \%(\mathrm{p}=0,487)$ respectivamente para SS e CS.

\subsubsection{Comparação do desempenho de PJ e CN no TLARC - versão CS}

Na comparação entre os grupos com relação a diagnóstico, os PJ relataram mais ansiedade $(p=0,025)$, enquanto que o grupo $C N$ relatou maior felicidade $(p=0,078)$ e maior confiança $(p=0,023)$. As variáveis comportamentais total de número digitados foi maior em $\mathrm{CN}$, o padrão de digitação $(\mathrm{p}=0,948)$ e o comportamento supersticioso $(\mathrm{p}=0,798)$ não apresentou diferenças entre os grupos, a transgressão $(0,163)$ e o desamparo $(0,720)$ foram mais frequentes em PJ, e o tempo até desistir $(p=0,467)$ e o tempo até acerto $(0,729)$ foram mais frequentes em CN. Entre as variáveis cognitivas, o grupo CN declarou usar mais estratégia $(p=0,209)$, os PJ declararam com mais frequência desistir de encontrar uma senha $(p=0,161)$, a percepção de controle teve uma diferença significativa $(p=0,046)$, com o $\mathrm{CN}$ tendo uma percepção mais assertiva da controlabilidade dessa versão em relação aos PJ. Além disso, a crença na existência de uma senha $(p=0,110)$, a convicção sobre a existência de uma senha $(p=0,146)$ e o acerto da senha $(p=0,225)$ foram mais frequentes no grupo $C N$. A tabela 8 resume os principais achados. 
Tabela 8 - Comparação de desempenho no teste longo de análise respostaconsequência (TLARC) entre portadores de Transtorno do Jogo (PJ) e controles normais $(C N)$ na versão com solução $(C S)(N=68)$

\begin{tabular}{|c|c|c|c|c|}
\hline Tipo de Resposta & PJ $(n=34)$ & $\mathrm{CN}(\mathrm{n}=34)$ & Coef. & $\mathbf{p}$ \\
\hline \multicolumn{5}{|l|}{ Afetiva: } \\
\hline Ansiedade - M (amplitude) & $3,0(0-10,0)$ & $1,6(0-10,0)$ & $\mathrm{U}=745,0$ & $\underline{0,025}$ \\
\hline Felicidade - M (amplitude) & $2,1(0-10,0)$ & $3,4(0-10,0)$ & $\mathrm{U}=443,5$ & 0,078 \\
\hline Confiança - M (amplitude) & $3,9(0-10,0)$ & $5,7(0-10,0)$ & $\mathrm{U}=339,5$ & $\underline{0,023}$ \\
\hline \multicolumn{5}{|l|}{ Comportamental: } \\
\hline $\begin{array}{l}\text { Total de número de dígitados - } \\
\mu \text { (DP) }\end{array}$ & $217,7(182,33)$ & $291(296,88)$ & $\mathrm{t}=1,226$ & 0,225 \\
\hline Padrão de digitação - $\mathrm{n}^{\circ}(\%)$ & & & $\mathrm{U}=574,5$ & 0,948 \\
\hline - Ausente (digitação aleatória) & $28(82 \%)$ & $28(82 \%)$ & $\chi^{2}=0$ & 1 \\
\hline $\begin{array}{l}\text { - Parcial I (aleatório > } \\
\text { combinatório) }\end{array}$ & $1(3 \%)$ & $2(6 \%)$ & $\chi^{2}=0,349$ & 0,555 \\
\hline $\begin{array}{l}\text { - Parcial II (combinatório > } \\
\text { aleatório) }\end{array}$ & $1(3 \%)$ & $1(3 \%)$ & $\chi^{2}=0$ & 1 \\
\hline $\begin{array}{l}\text { - Completo (digitação } \\
\text { combinatória) }\end{array}$ & $4(12 \%)$ & $3(9 \%)$ & $\chi^{2}=0,159$ & 0,690 \\
\hline $\begin{array}{l}\text { Comportamento supersticioso - } \\
\mathrm{n}^{\circ}(\%)\end{array}$ & $11(32 \%)$ & $12(35 \%)$ & $\chi^{2}=0,066$ & 0,798 \\
\hline Transgressão $-\mathrm{n}^{\circ}(\%)$ & $4(12 \%)$ & $1(3 \%)$ & $\chi^{2}=1,943$ & 0,163 \\
\hline Desamparo / desistiu - $\mathrm{n}^{\mathrm{o}}(\%)$ & $5(15 \%)$ & $4(12 \%)$ & $\chi^{2}=0,128$ & 0,720 \\
\hline $\begin{array}{l}\text { Número de tentativas até desistir } \\
-\mu \text { (DP) }\end{array}$ & $42,7(14,28)$ & $45,0(11,81)$ & $\mathrm{t}=0,731$ & 0,467 \\
\hline $\begin{array}{l}\text { Número de tentativas até acerto } \\
-\mu(\mathrm{DP})\end{array}$ & $9,7(12,69)$ & $10,8(13,05)$ & $\mathrm{t}=0,349$ & 0,729 \\
\hline \multicolumn{5}{|l|}{ Cognitiva: } \\
\hline $\begin{array}{l}\text { Declarou usar uma estratégia } \\
(\%)\end{array}$ & $19(55,9 \%)$ & $24(70,6 \%)$ & $\chi^{2}=1,581$ & 0,209 \\
\hline $\begin{array}{l}\text { Declarou desistir de encontrar } \\
\text { uma senha }-\mathrm{n}^{\circ}(\%)\end{array}$ & $11(32 \%)$ & $6(17,6 \%)$ & $\chi^{2}=1,961$ & 0,161 \\
\hline Percepção de controle $-\mu$ (DP) & $3,8(3,27)$ & $5,4(3,28)$ & $\mathrm{t}=2,035$ & $\underline{0,046}$ \\
\hline $\begin{array}{l}\text { Acreditou que o teste era } \\
\text { controlável }(\%)\end{array}$ & $21(61,7 \%)$ & $27(79,4 \%)$ & $\chi^{2}=2,550$ & 0,110 \\
\hline $\begin{array}{l}\text { Convicção sobre a existência de } \\
\text { uma senha-M (amplitude) }\end{array}$ & $6,8(0-10,0)$ & $8,4(3-10,0)$ & $\mathrm{U}=472,0$ & 0,146 \\
\hline $\begin{array}{l}\text { Acertou a senha (código } 31)- \\
\mathrm{n}^{\mathrm{o}}(\%)\end{array}$ & $13(38,2 \%)$ & $20(58,8 \%)$ & $\chi^{2}=2,981$ & 0,225 \\
\hline
\end{tabular}

Cinco variáveis que atingiram o limiar para significância potencial na comparação entre os grupos $(p<0,10)$ foram inseridas em uma regressão logística, tendo o grupo diagnóstico como variável dependente: ansiedade, confiança, felicidade, percepção de 
controle e tempo de desistência. Estado civil e status sócioeconômico foram adicionados para controle das variações no perfil demográfico. O modelo final foi significativo $\left(\chi^{2}\right.$ ${ }_{[2]}=28,235, \mathrm{p}<0,001 ; \mathrm{R}^{2}$ de Nagelkerke=0,453) com uma classificação correta de 51 (75\%) indivíduos. Duas variáveis permaneceram no modelo final: ansiedade $(\mathrm{OR}=1,44$, intervalo de confiança de 95\%: 1,11-1,88, $\mathrm{p}=0,07)$ e confiança $(\mathrm{OR}=0,79$, intervalo de confiança de 95\% 0,66-0,965, $\mathrm{p}=0,020)$, sendo a ansiedade maior para PJ quando comparados aos $\mathrm{CN}$, e a confiança maior para $\mathrm{CN}$ em relação ao PJ. A tabela 9 resume os principais achados.

Tabela 9 - Comparação de desempenho no teste longo de análise respostaconsequência (TLARC) entre portadores de Transtorno do Jogo (PJ) e controles normais $(\mathrm{CN})$ na versão com solução $(\mathrm{CS})$ (regressão logística, $\mathrm{N}=68$ )

\begin{tabular}{|c|c|c|c|c|c|c|}
\hline \multirow{2}{*}{ Diagnóstico } & \multirow{2}{*}{ B } & \multirow{2}{*}{$\chi^{2}$ de Wald } & \multirow{2}{*}{$\begin{array}{l}\text { Odds Ratio } \\
(\operatorname{Exp} \beta)\end{array}$} & \multicolumn{2}{|c|}{$\begin{array}{c}\text { Intervalo de } \\
\text { confiança } 95 \%\end{array}$} & \multirow{2}{*}{$\mathbf{p}$} \\
\hline & & & & Inferior & Superior & \\
\hline Estado civil & $-1,963$ & 8,907 & 0,140 & 0,390 & 0,510 & $\underline{0,003}$ \\
\hline $\begin{array}{l}\text { Status } \\
\text { socioeconômico }\end{array}$ & $-0,302$ & 7,131 & 0,740 & 0,593 & 0,923 & $\underline{0,008}$ \\
\hline Ansiedade & 0,367 & 7,359 & 1,444 & 1,107 & 1,883 & $\underline{0,007}$ \\
\hline Confiança & $-0,224$ & 5,402 & 0,799 & 0,662 & 0,965 & $\underline{0,020}$ \\
\hline
\end{tabular}

\subsubsection{Comparação do desempenho de PJ e CN no TLARC - versão SS}

$\mathrm{Na}$ comparação entre os grupos com relação a diagnóstico, a ansiedade foi mais frequente nos $\mathrm{PJ}(\mathrm{p}=0,573)$, enquanto que a felicidade e a confiança foram mais frequentes em $\mathrm{CN}(\mathrm{p}=0,443$ e $\mathrm{p}=0,004$, respectivamente). Quanto às variáveis comportamentais, verificamos que o total de números digitados foi maior em PJ em relação ao grupo $\mathrm{CN}(\mathrm{p}=0,020)$, o padrão de digitação aleatório não apresentou diferenças entre os grupos $(p=1)$, os PJ utilizaram com mais frequência estratégias parciais $(p=0,231$ e $\mathrm{p}=0,642$ ) e o grupo $\mathrm{CN}$ fez uso com mais frequência de um padrão combinatório completo $(p=0,203)$. O comportamento supersticioso ocorreu com mais frequência no grupo PJ $(p=0,028)$, bem como a transgressão também foi mais recorrente no grupo PJ $(p=0,310)$. O grupo $C N$ apresentou mais desamparo em relação aos $P J(p=0,300)$ e 
demorou menos tempo para desistir em relação aos $\mathrm{PJ}(\mathrm{p}=0,467)$. Já com relação às variáveis cognitivas, verificamos que o uso de estratégia foi mais frequente em $\mathrm{CN}$ do que em PJ $(p=0,451)$, a declaração de ter desistido de encontrar uma senha foi maior no grupo $\mathrm{CN}(\mathrm{p}=0,618)$, a percepção de comtrole e a crença na existência de uma senha ocorreram com mais frequência nos $\mathrm{PJ}(\mathrm{p}=0,725$ e $\mathrm{p}=0,720$, respectivamente) e a convicção quanto à existência de uma senha foi maior no grupo $\mathrm{CN}(\mathrm{p}=0,060)$. A tabela 10 resume os principais achados. 
Tabela 10 - Comparação de desempenho no teste longo de análise respostaconsequência (TLARC) entre portadores de Transtorno do Jogo (PJ) e controles normais $(\mathrm{CN})$ na versão sem solução $(\mathrm{SS})(\mathrm{N}=68)$

\begin{tabular}{|c|c|c|c|c|}
\hline Tipo de Resposta & PJ $(n=34)$ & $\mathrm{CN}(\mathrm{n}=\mathbf{3 4})$ & Coef. & $\mathbf{p}$ \\
\hline \multicolumn{5}{|l|}{ Afetiva: } \\
\hline Ansiedade - M (amplitude) & $3,11(0-10,0)$ & $2,72(0-7,0)$ & $\mathrm{U}=621,0$ & 0,573 \\
\hline Felicidade - M (amplitude) & $1,36(0-7,0)$ & $1,75(0-7,0)$ & $\mathrm{U}=524,0$ & 0,443 \\
\hline Confiança - M (amplitude) & $2,62(0-10,0)$ & $4,87(0-10,0)$ & $\mathrm{U}=353,5$ & $\underline{0,004}$ \\
\hline \multicolumn{5}{|l|}{ Comportamental: } \\
\hline $\begin{array}{l}\text { Total de número de dígitados - } \\
\mu \text { (DP) }\end{array}$ & $462,3(60,6)$ & $279,8(47,1)$ & $\mathrm{t}=-2,377$ & $\underline{0,020}$ \\
\hline Padrão de digitação - nº (\%) & & & $\mathrm{U}=552,0$ & 0,707 \\
\hline $\begin{array}{l}\text { - Ausente (digitação } \\
\text { aleatória) }\end{array}$ & $22(65 \%)$ & $22(65 \%)$ & $\chi^{2}=0$ & 1 \\
\hline $\begin{array}{l}\text { - Parcial I (aleatório > } \\
\text { combinatório) }\end{array}$ & $5(15 \%)$ & $2(6 \%)$ & $\chi^{2}=1,433$ & 0,231 \\
\hline $\begin{array}{l}\text { - Parcial II (combinatório > } \\
\text { aleatório) }\end{array}$ & $3(9 \%)$ & $2(6 \%)$ & $\chi^{2}=0,216$ & 0,642 \\
\hline $\begin{array}{l}\text { - Completo (digitação } \\
\text { combinatória) }\end{array}$ & $4(12 \%)$ & $8(23 \%)$ & $\chi^{2}=1,619$ & 0,203 \\
\hline $\begin{array}{l}\text { Comportamento supersticioso } \\
-\mathrm{n}^{\mathrm{o}}(\%)\end{array}$ & $20(59 \%)$ & $11(32 \%)$ & $\chi^{2}=4,802$ & $\underline{0,028}$ \\
\hline Transgressão $-\mathrm{n}^{\mathrm{o}}(\%)$ & $14(41 \%)$ & $10(29 \%)$ & $\chi^{2}=1,030$ & 0,310 \\
\hline Desamparo / desistiu - no $(\%)$ & $9(26 \%)$ & $13(38 \%)$ & $\chi^{2}=1,075$ & 0,300 \\
\hline $\begin{array}{l}\text { Número de tentativas até } \\
\text { desistir - } \mu \text { (DP) }\end{array}$ & $39,8(15,3)$ & $35,0(18,5)$ & $\mathrm{t}=0,731$ & 0,467 \\
\hline \multicolumn{5}{|l|}{ Cognitiva: } \\
\hline $\begin{array}{l}\text { Declarou usar uma estratégia } \\
(\%)\end{array}$ & $20(58,8 \%)$ & $23(67,6 \%)$ & $\chi^{2}=0,569$ & 0,451 \\
\hline $\begin{array}{l}\text { Declarou desistir de encontrar } \\
\text { uma senha }-\mathrm{n}^{\circ}(\%)\end{array}$ & $12(35 \%)$ & $14(41 \%)$ & $\chi^{2}=0,249$ & 0,618 \\
\hline $\begin{array}{l}\text { Percepção de controle }-\mu \\
\text { (DP) }\end{array}$ & $0,7(1,6)$ & $0,6(1,8)$ & $t=-0,353$ & 0,725 \\
\hline $\begin{array}{l}\text { Acreditou que o teste era } \\
\text { controlável }-\mathrm{n}^{\circ}(\%)\end{array}$ & $5(14,7 \%)$ & $4(11,8 \%)$ & $\chi^{2}=0,128$ & 0,720 \\
\hline $\begin{array}{l}\text { Convicção sobre a existência } \\
\text { de uma senha - M (amplitude) }\end{array}$ & $5,4(0-10,0)$ & $6,8(0-10,0)$ & $\mathrm{U}=431,0$ & 0,060 \\
\hline
\end{tabular}

Nessa segunda avaliação, quatro variáveis que atingiram o limiar para significância potencial na comparação entre os grupos $(p<0,10)$ foram inseridas em uma regressão logística, tendo o grupo diagnóstico como variável dependente: confiança, 
quantidade de números digitados, comportamento supersticioso e convicção sobre a existência de uma senha. Estado civil e status sócioeconômico foram adicionados para controle das variações no perfil demográfico. O modelo final foi significativo $\left(\chi_{[2]}^{2}=31,309, p=<0,001 ; R^{2}\right.$ de Nagelkerke=0,492) com uma classificação correta de 51 (75\%) indivíduos. Duas variáveis permaneceram no modelo final: confiança $(\mathrm{OR}=0,69$, intervalo de confiança de 95\%:0,55-0,88, p=0,03) e quantidade de números digitados $(\mathrm{OR}=1,00$, intervalo de confiança de $95 \% 1,00-1,01, \mathrm{p}=0,010)$, sendo a confiança maior para $\mathrm{CN}$ em relação ao $\mathrm{PJ}$ e a quantidade de números digitados maior para $\mathrm{PJ}$ em relação a CN. A tabela 11 apresenta um resumo do modelo final de regressão para a versão SS do TLARC.

Tabela 11 - Comparação de desempenho no teste longo de análise respostaconsequência (TLARC) entre portadores de Transtorno do Jogo (PJ) e controles normais $(\mathrm{CN})$, versão sem solução (SS) (regressão logística, $\mathrm{N}=68$ )

\begin{tabular}{|c|c|c|c|c|c|c|}
\hline Diagnóstico & B & $\begin{array}{l}\chi^{2} \text { de } \\
\text { Wald }\end{array}$ & $\begin{array}{l}\text { Odds Ratio } \\
(\operatorname{Exp} \beta)\end{array}$ & $\begin{array}{r}\text { Intery } \\
\text { confiar } \\
\text { Inferior }\end{array}$ & $\begin{array}{l}\text { alo de } \\
\text { ça } 95 \% \\
\text { Superior }\end{array}$ & $\mathrm{p}$ \\
\hline Estado civil & $-1,572$ & 5,722 & 0,208 & 0,57 & 0,753 & $\underline{0,017}$ \\
\hline $\begin{array}{l}\text { Status } \\
\text { socioeconômico }\end{array}$ & $-0,288$ & 7,418 & 0,749 & 0,609 & 0,922 & $\underline{0,006}$ \\
\hline Confiança & $-0,359$ & 8,708 & 0,698 & 0,550 & 0,886 & $\underline{0,003}$ \\
\hline Quantidade de dígitos & 0,003 & 6,658 & 1,003 & 1,001 & 1,005 & 0,010 \\
\hline
\end{tabular}

Model data: $\chi^{2}[2]=31,309 ; \mathrm{p}=<0,001 ; \mathrm{R}^{2}$ of Nagelkerke $=0,492$ 
6. DISCUSSÃO 


\section{DISCUSSÃO}

Estudos prévios sobre desamparo aprendido e ilusão de controle entre os PJ têm se baseado em modelos de reforço positivo que imitam o paradigma do jogo. Embora informativos, esses resultados não deixam claro se o desenvolvimento da ilusão de controle nessas situações é devido a um fator de risco inerente a esses indivíduos ou resultante da exposição repetida às apostas. $\mathrm{O}$ jogo de azar é uma atividade complexa cuja manutenção envolve tanto mecanismos de reforço positivo (premiação) quanto de reforço negativo (alívio de emoções negativas). Paradigmas não relacionados às apostas como os testes de análise de resposta-consequência são uma alternativa para verificar a predisposição de PJ a desenvolverem ilusão de controle e comportamento supersticioso, em um contexto diverso do jogo de azar e a partir de um paradigma de reforço negativo exclusivo.

$\mathrm{Na}$ comparação entre os grupos no primeiro e no segundo estudo, verificamos que as amostras tiveram diferenças sócio-demográficas semelhantes entre os grupos PJ e $\mathrm{CN}$, com diferenças somente na situação profissional (primeiro estudo) e no status sócioeconômico (segundo estudo), que são fatores correlacionados. No segundo estudo, também observamos que os PJ tiveram uma diferença estatisticamente significante no indicador de estado civil, o que pode estar relacionado aos prejuízos conjugais e familiares decorrentes da dependência de jogo e mais bem identificado na ampliação da amostra.

\subsection{Comparação entre versões CS e SS - TCARC e TLARC}

Com relação às variáveis afetivas, os resultados das presentes pesquisas confirmaram nossa hipótese inicial que a execução das versões SS seria mais estressante do que a execução das versões CS. De fato, os participantes referiram maior ansiedade, menos felicidade e menos confiança ao relizarem as versões SS em ambos os estudos.

Quanto às variáveis comportamentais, uma frequência mais alta de digitação durante a versão SS em ambos os estudos pode ter ocorrido pelo fato de que, na ausência de uma solução, mesmo indivíduos propensos a usar uma estratégia recorreram ao acaso

após várias tentativas mal-sucedidas. O segundo estudo, pelo fato de ser mais longo e, com isso, possibilitar ao participante identificar melhor a controlabilidade do teste, gerou 
maior quantidade de transgressões e um menor tempo de desistência na versão SS, demonstrando consistência interna nos testes. Ou seja, a falta de solução no TLARC levou os participantes a transgredirem mais, possivelmente na intenção de checar a veracidade das orientações dadas e a desistirem mais rápido ao perceberem que o teste não tinha solução. $\mathrm{Na}$ análise sobre o desamparo aprendido, no TCARC não foi possível identificar a ocorrência de desamparo aprendido, provavelmente devido à natureza breve do teste. No entanto, quando há o aumento da quantidade de tentativas no segundo estudo, verificamos um número significativo de participantes que relataram desistir e aguardaram o teste terminar na versão SS. Além disso, no TLARC o tempo que o participante demorou até desistir de continuar tentando foi significativamente menor no teste SS, o que mostra que eram necessárias mais que dez tentativas para se constatar a ocorrência do desamparo aprendido.

$\mathrm{Na}$ análise das variáveis cognitivas, em ambos os estudos verificamos que a maioria dos participantes consideraram a versão CS mais controlável, apresentaram mais convicção na resposta e tiveram mais percepção de controle, o que demonstra que a análise de qual versão era controlável foi feita corretamente tanto para o TCARC quanto para o TLARC; a percepção de que seria possível controlar o teste SS ocorreu, mas numa frequência muito menor em relação ao teste CS, o que evidencia que a ilusão de controle em um TLARC com feedback de erro é menos provável.

Com relação à taxa de concordância entre o registro do computador e o relatório verbal sobre o uso de uma estratégia combinatória, no TCARC os tipos de discordância foram estatisticamente diferentes nas versões CS e SS, sugerindo tipos de incongruência diferentes para cada versão. Por um lado, um número substancial de participantes pareceu usar uma estratégia sem estarem completamente cientes de fazê-lo na versão CS. Por outro lado, na versão SS, os participantes relataram usar uma estratégia sem que qualquer estratégia tivesse sido identificada no registro do computador. Juntos, esses achados sugerem que em uma situação controlável, na qual o objetivo da tarefa poderia ser atingido, os participantes tendem a recorrer a estratégias combinatórias mesmo sem perceberem; já em situações incontroláveis, nas quais o objetivo da tarefa não pode ser atingido, os participantes tendem a se enganar sobre o uso de uma estratégia analítica, assemelhando-se de certa forma a explicações pseudo-racionais fornecidas por PJ quando tentam justificar a continuação da dependência de jogo mesmo em face de consequências negativas (Delfabbro; Winefield, 2000; Benhsain et al., 2004). De modo geral, a 
comparação entre as versões CS e SS mostrou que os testes produziram as consequências esperadas, adicionando mais evidências à confiabilidade do nosso paradigma de análise resposta-consequência. No TLARC não houve diferenças significativas entre o relato verbal e o registro no computador em ambas as versões, sugerindo que o prolongamento do tempo teste favorece, talvez por cansaço, a deterioração do controle cognitivo e os equívocos sobre as estratégias efetivamente utilizadas.

\subsection{Comparação PJ e CN - TCARC e TLARC na versão CS}

Com relação às variáveis afetivas, verificamos que, em comparação com os $\mathrm{CN}$, de modo geral os PJ relataram menos conforto tanto no TCARC (mais ansiedade) como no TLARC (mais ansiedade e menos confiança). Podemos interpretar os resultados afetivos em PJ como um reflexo do fato de que os mesmos foram incluídos em ambos os estudos enquanto procuravam tratamento; nesse sentido, o sofrimento com as consequências negativas do jogo pode ter impactado na autoestima e influenciado no desempenho durante os testes; além disso, estudos anteriores mostram que indivíduos com bons níveis de autoestima subestimam a quantidade de feedback negativo que recebem (Gibson; Sanbonmatsu, 2004). Isso, somado ao fato de que a versão CS deixava claro quando o participante acertava ou errava, poderia explicar a reação emocional dos $\mathrm{CN}$ frente ao teste CS.

Quanto às variáveis comportamentais, observamos no TCARC uma predominância do padrão de digitação aleatória em PJ, o que sugere uma maior dificuldade na organização de uma estratégia para encontrar a senha correta. Nesse sentido, falta de uma estratégia organizada sugere comprometimento das funções executivas, como memória operacional e planejamento, que podem estar relacionados à impulsividade (Arnsten; Li, 2005) e sintomas de TDAH (Rodriguez-Jimenez et al., 2006; Romo et al., 2016). No TLARC não houve diferenças significativas entre PJ e CN, podendo significar que talvez o alongamento do tempo de teste deteriora o desempenho dos participantes. Ou seja, se o objetivo for avaliar o desempenho comportamental, o TCARC tem mais sensibilidade para identificar uma estratégia comportamental menos eficiente desde o princípio.

$\mathrm{Na}$ análise das variáveis cognitivas, no TCARC os PJ declararam com menos frequência do que $\mathrm{CN}$ ter usado alguma estratégia. Em ambos os testes, TCARC e 
TLARC, os PJ tiveram menor percepção de controlabilidade do teste, revelada tanto na sensação de um controle efetivo sobre o estímulo aversivo em TCARC como na crença menos frequente sobre a possibilidade de controle em TLARC. Esse ceticismo dos PJ pode ser um viés cognitivo produzido pela memória do insucesso em prever e controlar o jogo, e pode estar particularmente saliente no momento em que o indivíduo busca tratamento, como é o caso dessa amostra clínica. Mesmo em um cenário no qual o controle é uma possibilidade real como é o caso da versão CS, essa incredulidade reforça a percepção de que a construção da crença, seja favorável ou desfavorável ao controle, não é construída com base na análise racional das relações resposta-consequência, apontando para uma deficiência inata nos PJ. Assim, constroem-se crenças alternativas que, quando aleatoriamente reforçadas, podem contribuir para a consolidação de distorções cognitivas. Embora especulativo, é possível supor que em um contexto no qual o reforço positivo é mais proeminente, como no jogo de azar, organizam-se as distorções favoráveis ao controle e à vitória. Já em um ambiente diverso, como o do TCARC e TLARC, nos quais predominam as consequências aversivas, desenvolvem-se as distorções desfavoráveis ao controle, mesmo quando esse controle é possível.

Nos resultados da análise de regressão múltipla no TLARC, verificamos que os PJ relataram mais ansiedade e menos confiança durante a execução do teste; isso corrobora o dado de que o TJ tem alta associação com comorbidades como ansiedade e depressão (Jauregui; Estévez; Urbiola, 2016) e, em uma situação de reforço negativo como a dos testes aplicados nos dois estudos apresentados (TCARC e TLARC), a condição prévia dos PJ possivelmente favoreceu que os mesmos relatassem maior sofrimento frente à percepção de ineficácia durante a execução dos testes.

\subsection{Comparação PJ e CN - TCARC e TLARC na versão SS}

$\mathrm{Na}$ análise das variáveis emocionais nas versões SS, tanto no TCARC quanto no TLARC, mais uma vez os PJ expressaram menos conforto que os $\mathrm{CN}$ durante a realização dos testes, revelada no relato de mais ansiedade (TCARC) e menos confiança (TCARC e TLARC), corroborando a percepção de fragilidade emocional dos PJ que antecede e contamina o pano de fundo emocional em que os testes foram realizados.

Já na análise das variáveis comportamentais, a hipótese de que os PJ apresentariam menos desamparo aprendido nas versões SS (principalmente no TLARC) 
não foi estatisticamente confirmada. No entanto, a maior quantidade de números digitados em ambos os estudos mostra uma persistência maior da parte dos PJ associada a uma falha na percepção de controlabilidade do teste, o que sugere que quando os PJ estão imersos na busca de um resultado, seja em uma condição de análise de respostaconsequência ou em jogos de azar, há um expressivo aumento do comportamento mesmo frente a um feedback de erro ou fracasso. A associação entre uma maior quantidade de dígitos e uma menor confiança dos PJ também reforça nossa hipótese de que o sentimento negativo frente a uma situação incontrolável não impede o comportamento de apostar; pelo contrário, o jogo descontrolado possivelmente tem como função proteger a autoestima, mesmo que esse comportamento não resulte em qualquer consequência eficaz e bem-sucedida para o PJ. Além disso, os comportamentos supersticiosos foram mais frequentes nos PJ do que nos $\mathrm{CN}$ no TLARC, o que sugere que esses comportamentos têm maior probabilidade de ocorrerem em um contexto específico que envolve vulnerabilidade individual $(\mathrm{PJ})$, resultados arbitrários (versão SS) e tempo suficiente de exposição (TLARC).

Por fim, na análise das variáveis cognitivas verificamos que os PJ declararam com menos frequência ter usado alguma estratégia no TCARC. A falta de uma estratégia organizada sugere comprometimento das funções executivas, como memória operacional e planejamento, que impactam diretamente no desempenho dos PJ em tarefas de aprendizado e tomadas de decisão (Pecchinenda; Dretsch; Chapman, 2006, Nigro et al., 2019). Também verificamos que a crença em um código existente para controlar o ruído aversivo foi menor nos PJ nos dois estudos. Poderíamos considerar aqui que os PJ fizeram uma leitura correta quanto à controlabilidade da versão SS em ambos os estudos, e que os PJ tendem a desenvolver ilusão de controle durante tarefas de aprendizado associativo positivo, o que nos leva à conclusão de que, se houver probabilidade de ocorrer distorções cognitivas e ilusão de controle nos PJ, elas ocorreriam quando os comportamentos estivessem alinhados com um reforço positivo (como ocorre quando um PJ alcança o jackpot em uma máquina caça-níqueis). Portanto, uma explicação alternativa seria que, diferentemente do jogo, nossas tarefas carecem de estímulo associado ao reforço positivo que possa alimentar distorções cognitivas favoráveis e ilusão de controle.

Nos resultados da análise de regressão múltipla no TLARC, verificamos que os PJ apresentaram maior quantidade de digitações e menos confiança. Podemos especular 
que a maior quantidade de dígitos está relacionada a uma estratégia compensatória, na qual o indivíduo aumenta a taxa de resposta para contrabalançar a falta de confiança na eficácia do seu comportamento. Mais ainda, esse aumento de resposta é realizado por meio de respostas disparadas sem estratégia definida que reitera o caráter impulsivo e o déficit executivo (Chowdhury et al., 2017).

\subsection{Consequências clínicas}

Os modelos cognitivos mais recentes relacionados à dependência de jogo associam pensamentos irracionais e percepções errôneas a ilusão de controle, comportamento supersticioso, memória seletiva e vieses cognitivos (ex., falácia do jogador) como fatores fundamentais para o desenvolvimento e manutenção de padrões no comportamento de jogo (Joukhador; Maccallum; Blaszczynski, 2003). Nesse aspecto, nosso estudo demonstrou que mesmo em atividades não relacionadas ao comportamento de apostar ainda é possível identificar falhas no planejamento executivo dos PJ relacionadas ao uso de estratégias ineficazes para solução de problemas, o que indica a importância de uma abordagem terapêutica que contemple mecanismos de treino cognitivo, com ênfase em memória operacional (Luquiens et al., 2019). Podemos especular que, eventualmente a adoção de estratégias cognitivas mais eficazes permitiria a verificação da futilidade do jogo. Isto é, que independente das estratégias ensaiadas, o resultado permanece sendo o mesmo: o apostador não consegue controlar o resultado das apostas, semelhante à versão SS do TLARC. Ao invés disso, o PJ dispara respostas a esmo e eventualmente é recompensado por isso ao acaso, reforçando condutas supersticiosas e persistência do comportamento.

As evidências encontradas nas pesquisas também mostram que os PJ que procuram tratamento apresentam menos felicidade, menos autoconfiança e mais ansiedade, possivelmente por estarem em uma condição prejudicada do ponto de vista conjugal e socioeconômico. Nesse sentido, um ambiente adverso pode comprometer o desempenho frente a uma tarefa que envolve análise da relação resposta-consequência, como é o caso tanto dos paradigmas testados no presente estudo como nos jogos de azar. De fato, isso reforça a importância de um processo terapêutico estruturado para melhorar as estratégias de enfrentamento dos PJ (Petry et al., 2007), além de acompanhamento psicológico para lidar com os sentimentos negativos e autodestrutivos decorrentes dos 
prejuízos ocasionados com o jogo (Rosenthal, 2015).

\subsection{Limitações}

Ambos, TCARC e TLARC, apresentaram algumas limitações. Primeiro, a exclusão de PJ com comorbidades psiquiátricas graves pode ter tornado a amostra de PJ mais restritiva e, embora isso tivesse melhorado a validade interna da amostra (ou seja, diferenças entre PJ e CN são mais prováveis devido ao jogo do que a outras condições concorrentes), essa restrição pode comprometer a generalização dos achados para outros PJ, uma vez que os transtornos psiquiátricos comórbidos são mais a regra do que a exceção, especialmente em amostras baseadas em tratamento (Tavares et. al., 2001). De maneira semelhante, os critérios restritivos de inclusão resultaram em um tamanho reduzido da amostra, que é outra limitação importante. Para o estudo principal, os critérios de seleção dos PJ não incluíram tantas restrições quanto no estudo controle, mantendo somente o diagnóstico de TJ como fator fundamental para inclusão na amostra (além de outros quesitos como estabilidade de tratamento de outras psicopatologias, como já descrito no método). Além disso, aumentamos a amostra de 40 para 68 pessoas no segundo estudo, e também aumentamos de 10 para 50 repetições a fim de verificar como as mesmas variáveis independentes funcionavam nas condições CS e SS para cada grupo diagnóstico.

Foi feita uma escolha pelo uso do paradigma sem reforço positivo a fim de manter a comparabilidade com estudos anteriores usando o mesmo modelo, porém com algumas modificações. Primeiro, mantivemos um feedback de falha para determinar se os indivíduos desenvolveriam ilusão de controle, mesmo quando o oposto fosse explicitamente sinalizado. Segundo, no TCARC nossas versões de teste eram curtas de propósito para investigar fenômenos iniciais que poderiam acontecer antes que uma resposta comportamental fixa fosse alcançada, e isso foi posteriormente verificado no TLARC se se mantinha ou não. Terceiro, para facilitar a comparabilidade entre as versões tanto no TCARC quanto no TLARC, mantivemos uma duração fixa de cinco segundos para cada estímulo aversivo (a menos que o indivíduo digitasse o código correto na versão CS), com o intuito de facilitar a percepção de independência entre resposta e resultado na versão SS. 
7. CONCLUSÃO 


\section{CONCLUSÃO}

- Em ambos os testes, TCARC e TLARC, realizar a versão SS foi afetivamente mais desconfortável do que a versão CS, com maiores índices de ansiedade na versão SS e maiores índices de felicidade e confiança na versão CS, conforme o esperado;

- O desamparo aprendido ocorreu na versão SS conforme o previsto, porém somente no TLARC, mostrando que eram necessárias mais de 10 tentativas frustradas para que este fenômeno pudesse ser observado;

- O total de números digitados foi maior em ambos os testes na versão SS conforme o esperado. No TLARC, também observamos mais transgressão das regras na versão SS e menor número de tentativas, devido à desistência por desamparo aprendido;

- Não identificamos o desenvolvimento de ilusão de controle em nenhum dos testes ao contrário do que inicialmente previsto, possivelmente por causa do feedback de erro que preveniu a falsa percepção de controlabilidade da versão SS em ambos os testes;

- As tentativas de uso de estratégia combinatória foram igualmente frequentes nas versões CS e SS do TCARC e do TLARC. Porém, a percepção de controle, a crença na controlabilidade e a convicção na resposta foi maior na versão CS em ambos os testes como esperado, o que reforça a confiabilidade do paradigama utilizado;

- Conforme previsto, os PJ relataram mais desconforto emocional durante a realização do TCARC e do TLARC, porém isso foi verdadeiro apenas para as versões CS. As versões SS dos TCARC e TLARC foram experimentadas como igualmente estressantes por ambos os grupos diagnósticos, $\mathrm{CN}$ e PJ. O desconforto experimentado pelos PJ durante uma tarefa CS pode ser explicado em parte pelo momento em que foram submetidos aos testes, que correspondia à ocasião em que procuravam tratamento, geralmente no ápice do seu sofrimento subjetivo;

- Os PJ não apresentaram menos desamparo aprendido que $\mathrm{CN}$, persistindo mesmo nas versões SS de forma semelhante aos $\mathrm{CN}$, levando-nos a hipotetizar que se houvesse de fato uma resistência maior dos PJ ao desamparo aprendido, esta seria 
mais evidente na presença de reforço sem feedback de erro ou frente a reforço positivo com intervalos de tempo variados;

- De uma maneira geral, o desempenho dos PJ nos teste foi pior que os dos CN, conforme o esperado, com mais digitação aleatória no TCARC em ambas as versões CS e SS. Por outro lado, no TLARC o desempenho de ambos os grupos foi semelhante para a versão CS, enquanto na versão SS observou-se nos PJ mais comportamento esterotipado/supersticioso. Além disso, embora não tenhamos observado diferenças na frequência do desamparo aprendido entre os grupos, a maior frequência de digitações durante o TLARC na versão SS sugere uma tendência à persistência na tarefa, mesmo quando ela não apresenta solução possível;

- Ao contrário do previsto, de uma forma geral os PJ tiveram menos percepção de controle ao longo do TCARC e do TLARC, independente das versões CS e SS. Mais ainda, na versão SS do TCARC a ilusão de controle foi mais frequente em $\mathrm{CN}$ do que em PJ. A provável explicação para esse fato é que o paradigma testado no presente estudo não apresentou reforço positivo com intervalos de intermitência variados, fator que talvez fosse relevante para o aparecimento da ilusão de controle em PJ por ser uma característica paradigmática dos jogos de azar;

- Os PJ declararam usar menos estratégia no TCARC em ambas as versões, sugerindo menos disposição para realização de um controle cognitivo durante o teste. Interessantemente em TLARC, PJ e CN não se diferenciaram quanto à intenção do uso de estratégia para realização do teste, sugerindo que à medida que se prolonga o tempo de testagem, talvez os PJ percebam a necessidade de adoção de uma estratégia.

- Do conjunto dos resultados, o que mais sobressai é a frequência maior de digitação aleatória em PJ em ambos os testes, TCARC e TLARC, particularmente nas versões SS, sugerindo uma dificuldade no emprego de estratégias combinatórias simples por parte dos PJ, possivelmente decorrente de um déficit no controle cognitivo. O paradigma de análise resposta-consequência utilizado neste estudo não continha elementos pertinentes aos jogos de azar, isto é, esquema de reforçamento positivo intermitente e aleatório, diminuindo portanto a 
possibilidade de que o envolvimento prévio com jogos de azar fosse um determinante das diferenças de desempenho entre PJ e CN.

- Portanto, é possível especular que este déficit de controle cognitivo seja uma característica inerente ao $\mathrm{PJ}$, um traço que predispõe o indivíduo a privilegiar estratégias menos eficazes do tipo "tentativa e erro", aumentando a taxa de resposta comportamental (digitação) até que ocorra o resultado desejado. No contexto do jogo de azar, algumas dessas estratégias comportamentais menos eficazes seriam aleatoriamente recompensadas, produzindo ilusão de controle e persistência das apostas.

- Os modelos de tratamento atual de TJ colocam grande ênfase na restruturação cognitiva pautada em revisão das falsas assunções de controle dos resultados, porém nosso estudo mostrou que em contexto diverso e na presença de um feedback de erro enfático, a ilusão de controle não ocorre, mas a taxa de resposta permanece alta mesmo quando não há controle possível. Nossos achados podem ter implicações relevantes tanto para prevenção quanto para o tratamento do TJ. Primeiro, nosso reultados sugerem que um feedback mais explícito dos resultados negativos durante o jogo poderia ser uma estratégia efetiva para prevenção da ilusão de controle e persistência das apostas. Segundo, se durante o tratamento os PJ fossem treinados em habilidades úteis ao controle cognitivo, por exemplo memória operacional, isto permitiria uma apreciação mais acurada das relações entre resposta e consequência. Com isso, os pacientes poderiam perceber o esgotamento das respostas possíveis porque todas produzem a mesma consequência, isto é, o resultado é independente das ações, levando os PJ a cessarem as apostas reiteradas.

- Futuros estudos com variação de alguns parâmetros do teste analítico de respostaconsequência como a ausência do feedback de erro, reforço positivo ou intermitência de tempo variável podem proporcionar maior compreensão da transição de processos iniciais para respostas fixas no TJ, validar os testes de análise de resposta-consequência como ferramentas para avaliação de tratamento e finalmente auxiliar no desenvolvimento de modelos terapêuticos mais eficazes para o TJ. 
8. ANEXOS 


\section{ANEXOS}

ANEXO A - Termo de Consentimento Livre e Esclarecido (TCLE)

\section{DADOS DE IDENTIFICAÇÃO (OU ETIQUETA INSTITUCIONAL DE IDENTIFICAÇÃO) DO PARTICIPANTE DA PESQUISA OU RESPONSÁVEL LEGAL}

1. NOME DO PACIENTE

DOCUMENTO DE IDENTIDADE $\mathrm{N}^{\circ}$ :

SEXO : MASCULINO FEMININO

DATA NASCIMENTO: ........................

ENDEREÇO

CIDADE

$\mathrm{N}^{\mathrm{o}}$

APTO:

BAIRRO:

TELEFONE: DDD ( )

2.RESPONSÁVEL LEGAL

NATUREZA (grau de parentesco, tutor, curador etc.)

DOCUMENTO DE IDENTIDADE :

SEXO: $M \quad F$

DATA NASCIMENTO.: ....................

ENDEREÇO:

$\mathrm{N}^{\mathrm{o}}$

APTO:

BAIRRO:

CIDADE:

CEP: TELEFONE: DDD ..)..

\section{DADOS DA PESQUISA}

TÍTULO DA PESQUISA: Desamparo Aprendido e Ilusão de Controle em portadores de transtorno do jogo e controles normais

PESQUISADOR PRINCIPAL: Hermano Tavares

DEPARTAMENTO / INSTITUTO: PRO-AMJO / Instituto de Psiquiatria

Convidamos o(a) sr(a). a participar desta pesquisa sobre análise do desamparo aprendido e ilusão de controle. Sua participação será muito importante para que possamos desenvolver estudos sobre o tema e contribuir para as pesquisas relacionadas ao jogo patológico. Agrademos sua participação.

Justificativa e os objetivos da pesquisa: Permitir a compeensão do porquê algumas pessoas são mais propensas ao desenvolvimento da dependência do jogo e fornecer informações para a elaboração de trabalhos mais efetivos, além de auxílio à terapêutica daqueles que intencionam parar de jogar.

Procedimentos e propósitos: Aplicação de teste em computador e questionário para os participantes (portadores de transtorno do jogo e controles normais) sobre esse teste.

Não há desconforto ou risco esperados. 
Os benefícios esperados são o desenvolvimento do conhecimento científico relacionado ao tema do jogo patológico.

Os portadores de transtorno do jogo poderão buscar apoio no PRO_AMJO a qualquer momento confome as regras do ambulatório, independente do andamento desse estudo.

Os participantes terão plena liberdade de recusar-se a participar ou retirar seu consentimento a qualquer momento sem penalização alguma de sigilo, privacidade ou assistência.

O termo de consentimento deve ser feito em 2 vias e o pesquisador e o participante deverão rubricar todas as vias. O participante receberá uma via do termo de consentimento.

O participante tem todas as garantias de ressarcimento por despesas decorrentes da pesquisa e garantia de indenização por eventuais danos decorrentes da pesquisa.

Em qualquer etapa do estudo, você terá acesso aos profissionais responsáveis pela pesquisa para esclarecimento de dúvidas. Você poderá entrar em contato com os pesquisadores pelo tel.: (11) 2661-7805. O principal investigador é o Dr. Hermano Tavares que pode ser encontrado no endereço: R. Ovídio Pires de Campos 785; Telefone(s) 3814-3920, e-mail hermanot@uol.com.br. Se você tiver alguma consideração ou dúvida sobre a ética da pesquisa, entre em contato com o Comitê de Ética em Pesquisa (CEP) - Rua Ovídio Pires de Campos, 225 - 5 andar - tel: (11) 2661- 6442 ramais 16, 17, 18, ou (11) 2661-7585; e-mail: cappesq.adm@hc.fm.usp.br

Fui suficientemente informado a respeito do estudo "Desamparo Aprendido e Ilusão de Controle em portadores de transtorno do jogo e controles normais".

Eu discuti as informações acima com o Pesquisador Responsável (Hermano Tavares) ou pessoa (s) por ele delegada (s) (Raquel Berg) sobre a minha decisão em participar nesse estudo. Ficaram claros para mim os objetivos, os procedimentos, os potenciais desconfortos e riscos e as garantias. Concordo voluntariamente em participar deste estudo, assino este termo de consentimento e recebo um via rubricada pelo pesquisador.

Assinatura do participante/representante legal Data: '

Assinatura do responsável pelo estudo Data 
ANEXO B - Questionário aplicado após o teste no computador

DATA DA AVALIAÇÃO: $\bar{l} /{ }^{\prime}-$ ( ) M ( ) F
NOME DO PARTICIPANTE:

GRUPO:

( ) Portadores de Trantorno do Jogo

( ) Controles Normais

Por favor, responda as questões abaixo a partir dos testes com ruídos que você fez no computador:

As seguintes perguntas A e B se referem A AMBOS OS TESTES.

A) Você utilizou uma estratégia para o primeiro teste, e outra DIFERENTE para o segundo teste?

$\circ$ SIM ○ NÃO.

B) Assinale a alternativa que lhe parece verdadeira:

a) Havia uma senha para controlar o $1^{\circ}$ teste e outra para controlar o $2^{\circ}$ teste.

b) Havia apenas uma senha que controlava o $1^{\circ}$ teste e o $2^{\circ}$ teste.

c) Não havia senha para o $1^{\circ}$ teste, nem para o $2^{\circ}$ teste.

d) Havia senha para o $1^{\circ}$ teste, mas não havia senha para o $2^{\circ}$ teste.

e) Havia senha para o $2^{\circ}$ teste, mas não havia senha para $o 1^{\circ}$ teste.

As questões de 1.1 a 1.10 se referem ao PRIMEIRO TESTE FEITO

1.1) Explique como você fez para tentar parar o ruído no primeiro teste (quais foram suas hipóteses até chegar a uma conclusão)?

1.2a) Havia uma senha para parar o ruído?

○ SIM ○ NÃO.

1.2b) Se SIM, qual é essa senha? 
1.3) Quão certo você está desta resposta (se SIM ou se NÃO)?

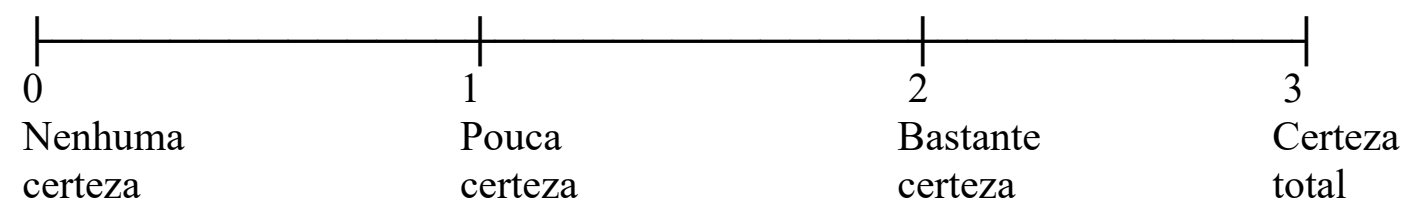

1.4) Aproximadamente, qual a porcentagem de ruídos que você acredita ter sido capaz de interromper no teste todo? (de 0 a 100).

\begin{tabular}{llll}
\hline & & & \\
0 & $25 \%$ & $75 \%$ & $100 \%$ \\
Não consegui & Controlei menos & Controlei mais & Controlei \\
controlar nenhum & da metade & da metade & todos os \\
ruídos & ruído & dos ruídos & dos ruídos
\end{tabular}

1.5) Se você acha que NÃO havia uma senha, o que você fez durante o teste?

1.6) No momento em que estava fazendo o teste, você se sentiu $\underline{\text { ANSIOSO? }}$

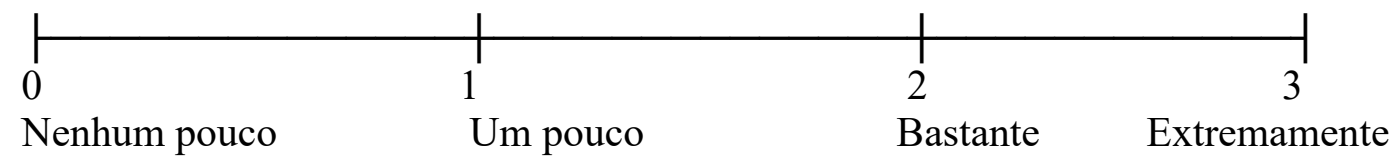

1.7) No momento em que estava fazendo o teste, você sentiu TRISTE?

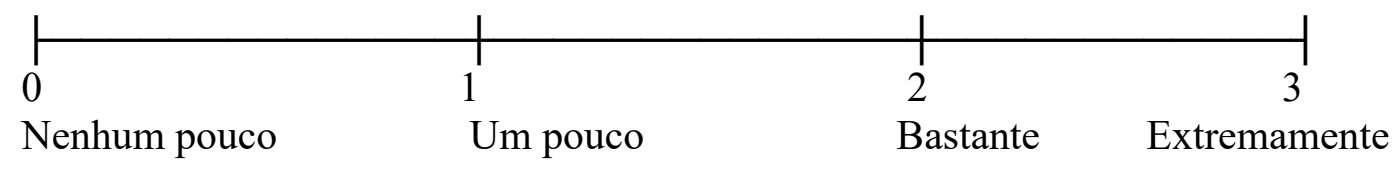

1.8) No momento em que estava fazendo o teste, você se sentiu FELIZ?

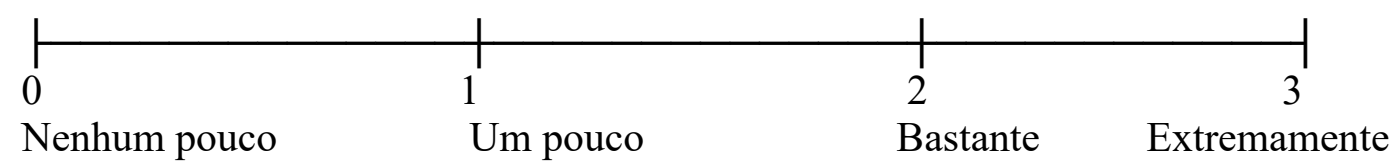

1.9) No momento em que estava fazendo o teste, você se sentiu CONFIANTE?

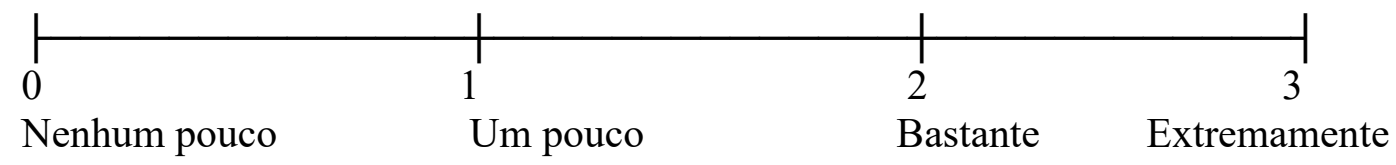


1.10) No momento em que estava fazendo o teste, você se sentiu $\underline{\text { CALMO}}$ ?

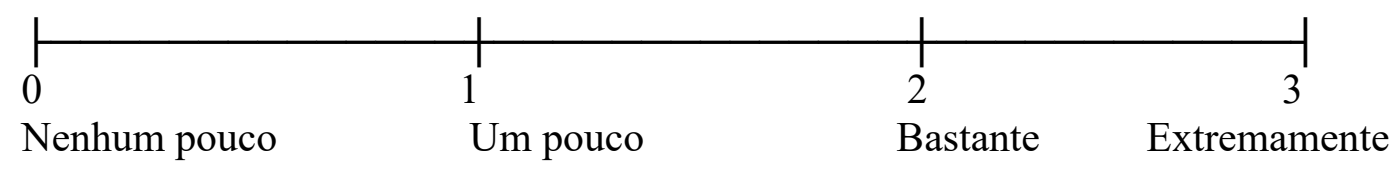

AGORA, as questões de 2.1 a 2.10 se referem ao SEGUNDO TESTE FEITO

2.1) Explique como você fez para tentar parar o ruído no segundo teste (quais foram suas hipóteses até chegar a uma conclusão)?

2.2a) Havia uma senha para parar o ruído?

$\circ$ SIM ○ NÃO.

2.2b) Se SIM, qual é essa senha?

2.3) Quão certo você está desta resposta (se SIM ou se NÃO)?

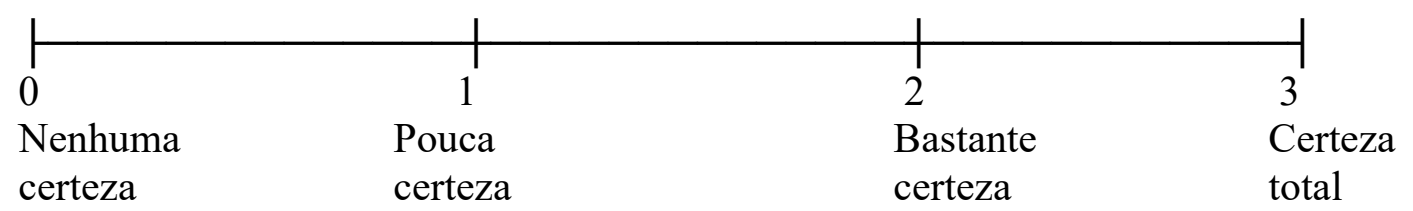

2.4) Aproximadamente, qual a porcentagem de ruídos que você acredita ter sido capaz de interromper no teste todo? (de 0 a 100).

\begin{tabular}{llll}
\hline & & & \\
0 & $25 \%$ & $75 \%$ & $100 \%$ \\
Não consegui & Controlei menos & Controlei mais & Controlei \\
controlar nenhum & da metade & da metade & todos os \\
ruídos & ruído & dos ruídos & dos ruídos
\end{tabular}

2.5) Se você acha que NÃO havia uma senha, o que você fez durante o teste? 
2.6) No momento em que estava fazendo o teste, você se sentiu $\underline{\text { ANSIOSO? }}$

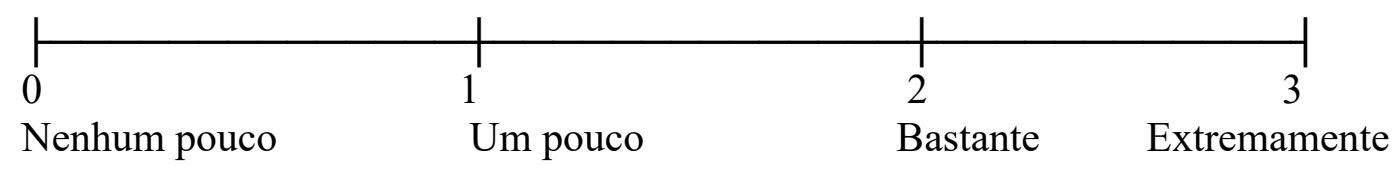

2.7) No momento em que estava fazendo o teste, você sentiu TRISTE?

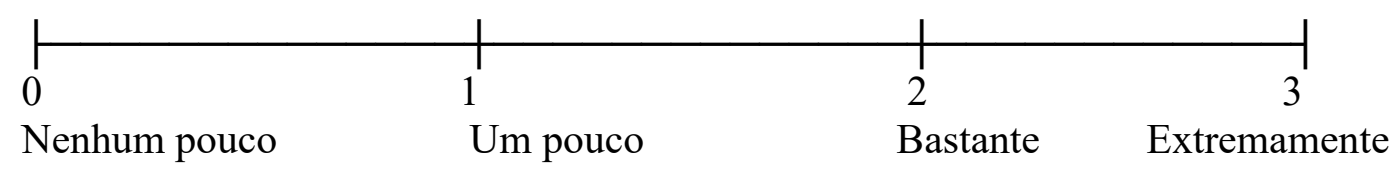

2.8) No momento em que estava fazendo o teste, você se sentiu FELIZ?

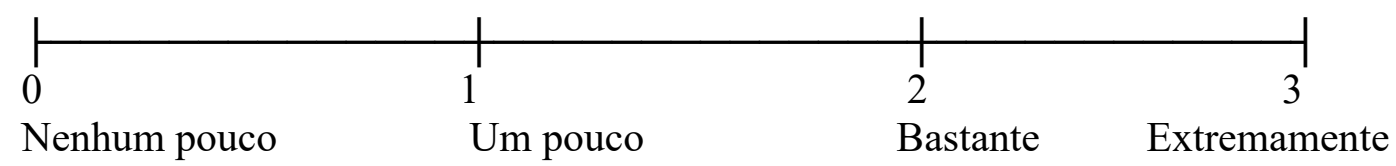

2.9) No momento em que estava fazendo o teste, você se sentiu CONFIANTE?

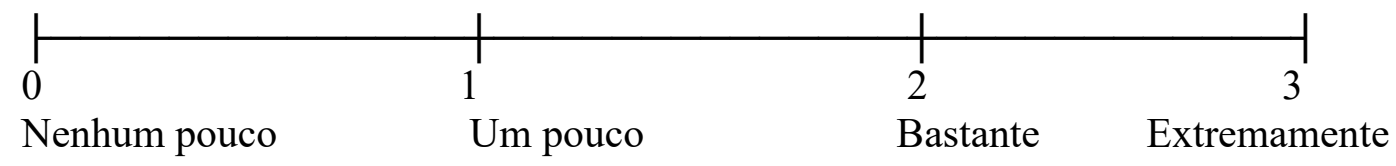

2.10) No momento em que estava fazendo o teste, você se sentiu CALMO?

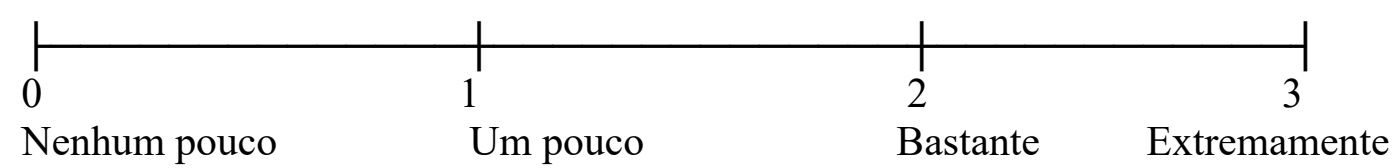

Agradecemos sua participação. 
ANEXO C - Artigo publicado

Citation text: Berg R; Kim HS; Hodgins DC; Tavares H. Uncovering underlying processes before illusion of control begins in gambling disorder: a pilot study. J Gambl Stud. 2020;36(3):829-849. 
9. REFERÊNCIAS 


\section{REFERÊNCIAS}

Abreu PR. Novas relações entre as interpretações funcionais do desamparo aprendido e do modelo comportamental de depressão. Psic Reflex Crit. 2011;24(4):788-98.

American Psychiatric Association. Diagnostic and Statistical Manual of Mental Disorders. 3rd ed. Washington (DC): APA; 1980.

American Psychiatric Association. Diagnostic and Statistical Manual of Mental Disorders. 5th ed. Arlington: APA; 2013.

Amorim P. Mini International Neuropsychiatric Interview (MINI): validação de entrevista breve para diagnóstico de transtornos mentais. Braz J Psychiatry. 2000;22(3):106-15.

Aragay N, Jimenez-Murcia S, Granero R, Fernández-Aranda F, Ramos-Grille I, Cardona S, et al. Pathological gambling: understanding relapses and dropouts. Compr Psychiatry. 2015;57:58-64.

Araujo AC, Neto FL. A Nova Classificação Americana Para os Transtornos Mentais - o DSM-5. Rev Bras de Ter Comp Cogn. 2014;16(1):67-82.

Archer M, Harwood H, Stevelink S, Rafferty L, Greenberg N. Community reinforcement and family training and rates of treatment entry: a systematic review. Addiction. 2020;115(6):1024-37.

Arnsten AFT, Li B-M. Neurobiology of executive functions: catecholamine influences on prefrontal cortical functions. Biol Psychiatry. 2005;57(11):1377-84.

Barrault S, Varescon I. Cognitive distortions, anxiety, and depression among regular and pathological gambling online poker players. Cyberpsychol Behav Soc Netw. 2013;16(3):183-8.

Barreto do Carmo MB, Santos LMD, Feitosa CA, Fiaccone RL, Silva NB da, Santos DND, et al. Screening for common mental disorders using the SRQ-20 in Brazil: what are the alternative strategies for analysis? Braz J Psychiatry. 2018;40(2):115-22. 
Benhsain K, Taillefer A, Ladouceur R. Awareness of independence of events and erroneous perceptions while gambling. Addict Behav. 2004;29(2):399-404.

Biolcati R, Passini S, Griffiths MD. All-in and Bad Beat: Professional Poker Players and Pathological Gambling. Int J Ment Health Addiction. 2015;13(1):19-32.

Bond A, Lader M. The use of analogue scales in rating subjective feelings. $\mathrm{Br} J \mathrm{Med}$ Psychol. 1974;47(3):211-8.

Boynton DM. Superstitious responding and frequency matching in the positive bias and gambler's fallacy effects. Organ Behav Hum Decis Process. 2003;91(2):119-27.

Brasil. Instituto Brasileiro de Geografia e Estatística. Pesquisa Nacional por Amostra de Domicílios - PNAD. Brasilia (DF): IBGE; 1998.

Buja A, Lion C, Scioni M, Vian P, Genetti B, Vittadello F, et al. SOGS-RA gambling scores and substance use in adolescents. J Behav Addict. 2017;6(3):425-33.

Cantinotti M, Ladouceur R, Jacques C. Sports betting: can gamblers beat randomness? Psychol Addict Behav. 2004;18(2):143-7.

Carneiro E, Tavares H, Sanches M, Pinsky I, Caetano R, Zaleski M, et al. Gambling onset and progression in a sample of at-risk gamblers from the general population. Psychiatry Res. 2014;216(3):404-11.

Carneiro E, Tavares H, Sanches M, Pinsky I, Caetano R, Zaleski M, et al. Gambling onset and progression in a sample of at-risk gamblers from the general population. Psychiatry Res. 2014;216(3):404-11.

Carvalho SVB de, Collakis ST, Oliveira MPMT de, Silveira DX da. Freqüência de jogo patológico entre farmacodependentes em tratamento. Rev Saúde Pública. $2005 ; 39(2): 217-22$.

Chowdhury NS, Livesey EJ, Blaszczynski A, Harris JA. Pathological Gambling and Motor Impulsivity: A Systematic Review with Meta-Analysis. J Gambl Stud. 2017;33(4):1213-39. 
Cowie ME, Stewart SH, Salmon J, Collins P, Al-Hamdani M, Boffo M, et al. Distorted Beliefs about Luck and Skill and Their Relation to Gambling Problems and Gambling Behavior in Dutch Gamblers. Front Psychol. 2017;8:2245.

Crockford DN, Goodyear B, Edwards J, Quickfall J, el-Guebaly N. Cue-Induced Brain Activity in Pathological Gamblers. Biol Psychiatry. 2005;58(10):787-95.

Delfabbro P. The stubborn logic of regular gamblers: obstacles and dilemmas in cognitive gambling research. J Gambl Stud. 2004;20(1):1-21.

Delfabbro PH, Winefield AH. Predictors of irrational thinking in regular slot machine gamblers. J Psychol. 2000;134(2):117-28.

Dixon MJ, Larche CJ, Stange M, Graydon C, Fugelsang JA. Near-Misses and Stop Buttons in Slot Machine Play: An Investigation of How They Affect Players, and May Foster Erroneous Cognitions. J Gambl Stud. 2018;34(1):161-80.

Dostoevsky FM. Um jogador: apontamentos de um homem moço. São Paulo: Editora 34; 2004.

Eyzop E, Vanier A, Leboucher J, Morvan H, Poulette M, Grall-Bronnec M, et al. Materialism, Financial Motives and Gambling: Examination of an Unexplored Relationship. J Gambl Stud. 2019;35(3):861-73.

Fauth-Bühler M, Mann K, Potenza MN. Pathological gambling: a review of the neurobiological evidence relevant for its classification as an addictive disorder: Pathological gambling. Addict Biol. 2017;22(4):885-97.

Ferentzy P, Turner NE. The history of problem gambling: temperance, substance abuse, medicine, and metaphors. New York: Springer; 2013.

Ferreira DC, Tourinho EZ. Desamparo aprendido e incontrolabilidade: relevância para uma abordagem analítico-comportamental da depressão. Psic: Teor e Pesq. 2013;29(2):211-9. 
Fong LHN, Lam D, Fong DKC. Controllable superstition and its relationship with enduring and behavioural involvement in gambling. Int Gambl Stud. 2018;18(1):92-110.

Gainsbury SM. Online Gambling Addiction: the Relationship Between Internet Gambling and Disordered Gambling. Curr Addict Rep. 2015;2(2):185-93.

Gibson B, Sanbonmatsu DM. Optimism, Pessimism, and Gambling: The Downside of Optimism. Pers Soc Psychol Bull. 2004;30(2):149-60.

Goodie AS. The effects of control on betting: paradoxical betting on items of high confidence with low value. J Exp Psychol Learn Mem Cogn. 2003;29(4):598-610.

Grant JE, Potenza MN, organizadores. Pathological gambling: a clinical guide to treatment. 1st ed. Washington (DC): American Psychiatric Pub; 2004.

Hiroto DS, Seligman ME. Generality of learned helplessness in man. J Pers Soc Psychol. $1975 ; 31(2): 311-27$.

Hodgins DC, Stea JN, Grant JE. Gambling disorders. Lancet. 2011;378(9806):1874-84.

Hunziker MHL. Desamparo aprendido [tese livre-docência]. São Paulo: Instituto de Psicologia, Universidade de São Paulo, São Paulo, 2003.

Jauregui P, Estévez A, Urbiola I. Pathological Gambling and Associated Drug and Alcohol Abuse, Emotion Regulation, and Anxious-Depressive Symptomatology. J Behav Addict. 2016;5(2):251-60.

Johnson EE, Hamer RM, Nora RM. The Lie/Bet Questionnaire for screening pathological gamblers: a follow-up study. Psychol Rep. 1998;83(3 Pt 2):1219-24.

Joukhador J, Blaszczynski A, Maccallum F. Superstitious Beliefs in Gambling Among Problem and Non-Problem Gamblers: Preliminary Data. J Gambl Stud. 2004;20(2):17180.

Joukhador J, Maccallum F, Blaszczynski A. Differences in Cognitive Distortions between Problem and Social Gamblers. Psychol Rep. 2003;92(Suppl 3):1203-14. 
Kim J (Sunny), Ahlgren MB, Byun J-W, Malek K. Gambling motivations and superstitious beliefs: a cross-cultural study with casino customers. Int Gambl Stud. 2016;16(2):296-315.

Kim HS, Christianini AR, Bertoni D, de Oliveira M do CM, Hodgins DC, Tavares H. Kleptomania and Co-morbid addictive disorders. Psychiatry Res. 2017;250:35-7.

Krueger THC, Schedlowski M, Meyer G. Cortisol and Heart Rate Measures during Casino Gambling in Relation to Impulsivity. Neuropsychobiology. 2005;52(4):206-11.

Kruglanski AW, Gigerenzer G. Intuitive and deliberate judgments are based on common principles. Psychol Rev. 2011;118(1):97-109.

Langer EJ. The illusion of control. J Pers Soc Psychol. 1975;32(2):311-28.

Lorains FK, Dowling NA, Enticott PG, Bradshaw JL, Trueblood JS, Stout JC. Strategic and non-strategic problem gamblers differ on decision-making under risk and ambiguity. Addiction. 2014;109(7):1128-37.

Luquiens A, Miranda R, Benyamina A, Carré A, Aubin H-J. Cognitive training: A new avenue in gambling disorder management? Neurosci Biobehav Rev. 2019;106:227-33.

Magalhães ACN, Jungerman FS, Silva MC, Moraes MM de, Tavares H. Post-therapy group for pathological gamblers: improvement beyond symptoms. Braz J Psychiatry. 2009;31(2):181-2.

Makridakis S, Moleskis A. The costs and benefits of positive illusions. Front Psychol. 2015;6:859.

Mann K, Fauth-Bühler M, Higuchi S, Potenza MN, Saunders JB. Pathological gambling: a behavioral addiction: Pathological gambling: a behavioral addiction. World Psychiatry. 2016;15(3):297-8.

Marazziti D, Catena Dell'osso M, Conversano C, Consoli G, Vivarelli L, Mungai F, et al. Executive function abnormalities in pathological gamblers. Clin Pract Epidemiol Ment Health. 2008;4:7. 
Martins SS, Lobo DSS, Tavares H, Gentil V. Pathological gambling in women: a review. Rev Hosp Clin. 2002;57(5):235-42.

Matarazzo O, Carpentieri M, Greco C, Pizzini B. The gambler's fallacy in problem and non-problem gamblers. J Behav Addict. 2019;8(4):754-69.

Matute H. Learned Helplessness and Superstitious Behavior as Opposite Effects of Uncontrollable Reinforcement in Humans. Learn Motiv. 1994;25(2):216-32.

Matute H. Human reactions to uncontrollable outcomes: further evidence for superstitious rather than helplessness. Q J Exp Psychol. 1995;48B(2):142-57.

Matute H. Illusion of Control: Detecting Response-Outcome Independence in Analytic but Not in Naturalistic Conditions. Psychol Sci. 1996;7(5):289-93.

McMillen J. Gambling cultures: studies in history and interpretation. London; Routledge; 2005.

McGrath DS, Kim HS, Hodgins DC, Novitsky C, Tavares H. Who Are the Anonymous? Involvement and Predictors of Gamblers Anonymous Attendance Among Disordered Gamblers Presenting for Treatment. J Gambl Stud. 2018;34(4):1423-34.

Medeiros GC, Sampaio DG, Leppink EW, Chamberlain SR, Grant JE. Anxiety, Gambling Activity, and Neurocognition: A Dimensional Approach to a Non-TreatmentSeeking Sample. J Behav Addict. 2016;5(2):261-70.

Myrseth H, Brunborg GS, Eidem M. Differences in cognitive distortions between pathological and non-pathological gamblers with preferences for chance or skill games. J Gambl Stud. 2010;26(4):561-9.

Nelson SE, LaPlante DA, Peller AJ, Schumann A, LaBrie RA, Shaffer HJ. Real Limits in the Virtual World: Self-Limiting Behavior of Internet Gamblers. J Gambl Stud. 2008;24(4):463-77.

Nestler EJ, Malenka RC. The Addicted Brain. Sci Am. 2004;290(3):78-85. 
Nichols MW, Stitt BG, Giacopassi D. Changes in Suicide and Divorce in New Casino Jurisdictions. J Gambl Stud. 2004;20(4):391-404.

Nigro G, Ciccarelli M, Cosenza M. Tempting fate: Chasing and maladaptive personality traits in gambling behavior. Psychiatry Res. 2018;267:360-7.

Nigro G, D’Olimpio F, Ciccarelli M, Cosenza M. The fuzzy future: Time horizon, memory failures, and emotional distress in gambling disorder. Addict Behav. 2019;97:713.

Oliveira MPMT de, Silveira DX da, Silva MTA. Jogo patológico e suas conseqüências para a saúde pública. Rev Saúde Pública. 2008;42(3):542-9.

Orgaz C, Estévez A, Matute H. Pathological gamblers are more vulnerable to the illusion of control in a standard associative learning task. Front Psychol. 2013;4:306.

Otto JL, Smolenski DJ, Garvey Wilson AL, Evatt DP, Campbell MS, Beech EH, et al. A systematic review evaluating screening instruments for gambling disorder finds lack of adequate evidence. J Clin Epidemiol. 2020;120:86-93.

Parhami I, Mojtabai R, Rosenthal RJ, Afifi TO, Fong TW. Gambling and the Onset of Comorbid Mental Disorders: A Longitudinal Study Evaluating Severity and Specific Symptoms. J Psychiatr Pract. 2014;20(3):207-19.

Pecchinenda A, Dretsch M, Chapman P. Working Memory Involvement in EmotionBased Processes Underlying Choosing Advantageously. Exp Psychol. 2006;53(3):1917.

Perales JC, Navas JF, Ruiz de Lara CM, Maldonado A, Catena A. Causal Learning in Gambling Disorder: Beyond the Illusion of Control. J Gambl Stud. 2017;33(2):705-17.

Petry NM, Litt MD, Kadden R, Ledgerwood DM. Do coping skills mediate the relationship between cognitive-behavioral therapy and reductions in gambling in pathological gamblers? Addiction. 2007;102(8):1280-91 
Petry NM, Stinson FS, Grant BF. Comorbidity of DSM-IV pathological gambling and other psychiatric disorders: results from the National Epidemiologic Survey on Alcohol and Related Conditions. J Clin Psychiatry. 2005;66(5):564-74.

Reuter J, Raedler T, Rose M, Hand I, Gläscher J, Büchel C. Pathological gambling is linked to reduced activation of the mesolimbic reward system. Nat Neurosci. 2005;8(2):147-8.

Rodriguez-Jimenez R, Avila C, Jimenez-Arriero MA, Ponce G, Monasor R, Jimenez M, et al. Impulsivity and sustained attention in pathological gamblers: influence of childhood ADHD history. J Gambl Stud. 2006;22(4):451-61.

Rogier G, Picci G, Velotti P. Struggling with Happiness: A Pathway Leading Depression to Gambling Disorder. J Gambl Stud. 2019;35(1):293-305.

Romo L, Legauffre C, Guilleux A, Valleur M, Magalon D, Fatséas M, et al. Cognitive distortions and ADHD in pathological gambling: A national longitudinal case-control cohort study. J Behav Addict. 2016;5(4):649-57.

Rosenthal RJ. Pathological Gambling. Psychiatr Ann. 1992;22(2):72-8.

Rosenthal RJ. Masochism and Pathological Gambling. Psychodyn Psychiatry. 2015;43(1):1-25.

Rosner B. Fundamentals of biostatistics. 7th ed. Boston: Brooks/Cole, Cengage Learning; 2011.

Samelo MJ. Desamparo aprendido e imunização em humanos: avaliação metodológica / conceitual e uma proposta experimental [tese]. São Paulo: Instituto de Psicologia, Universidade de São Paulo; 2012.

Schwartz DG. Roll the bones: the history of gambling (casino edition). Winchester: Winchester Books; 2013. 456 p.

Schützwohl M, Kallert T, Jurjanz L. Using the Schedules for Clinical Assessment in Neuropsychiatry (SCAN 2.1) as a diagnostic interview providing dimensional measures: 
cross-national findings on the psychometric properties of psychopathology scales. Eur Psychiatry. 2007;22(4):229-38.

Steenbergh TA, Meyers AW, May RK, Whelan JP. Development and validation of the Gamblers’ Beliefs Questionnaire. Psychol Addict Behav. 2002;16(2):143-9.

SPSS: Statistical Package for the Social Sciences, Version 18 for Windows. [computer program]. Chicago, Il: IBM SPSS Statistics; 2019.

Tavares H, Carneiro E, Sanches M, Pinsky I, Caetano R, Zaleski M, et al. Gambling in Brazil: Lifetime prevalences and socio-demographic correlates. Psychiatry Res. 2010;180(1):35-41.

Tavares H. Gambling in Brazil: a call for an open debate: Gambling in Brazil. Addiction. 2014;109(12):1972-6.

Tavares H, Gentil V. Pathological gambling and obsessive-compulsive disorder: towards a spectrum of disorders of volition. Braz J Psychiatry. 2007;29(2):107-17.

Tavares H, Zilberman ML, Beites FJ, Gentil V. Gender differences in gambling progression. J Gambl Stud. 2001;17(2):151-9.

Tobias-Webb J, Limbrick-Oldfield EH, Gillan CM, Moore JW, Aitken MRF, Clark L. Let me take the wheel: Illusory control and sense of agency. $Q J$ Exp Psychol. 2017;70(8):1732-46.

Toneatto T. Cognitive Psychopathology of Problem Gambling. Subst Use Misuse. 1999;34(11):1593-604.

Wemm SE, Cao Z, Han L, Wulfert E. Stress responding and stress-related changes in cue reactivity in heavy smokers, problem gamblers, and healthy controls. Addict Biol. 2020;25(2):e12687.

Wiehler A, Peters J. Reward-based decision making in pathological gambling: the roles of risk and delay. Neurosci Res. 2015;90:3-14. 
Williams WA, Potenza MN. Neurobiologia dos transtornos do controle dos impulsos. Braz J Psychiatry. 2008;30(Suppl 1):S24-30.

Wohl MJA, Enzle ME. The Deployment of Personal Luck: Sympathetic Magic and Illusory Control in Games of Pure Chance. Pers Soc Psychol Bull. 2002;28(10):1388-97.

World Health Organization. The ICD-11 classification of mental and behavioural disorders: diagnostic criteria for research. 11th ed. Geneva, 2018.

World Medical Association. Declaration of Helsinki: recommendations guiding physicians in biomedical research involving human subjects. JAMA. 1997;277(11):9256. 